\title{
ESTUDO DO COMPORTAMENTO DO POTÁSSIO EM SOLOS QUE RECEBERAM QUANTIDADES VARIÁVEIS DE MINÉRIOS VERMICULITICOS
}

\author{
MARLENE ESTEVÃO MARCHETTI
}

Orientador: Prof. Dr. RONALDO I. SILVEIRA

Dissertação apresentada à Escola Superior de Agricultura "Luiz de Queiroz", da Universidade de São Paulo, para obtenção do título de Mestre em Agronomia. Área de Concentração: Solos e Nutrição de Plantas.

PIRACICABA

Estado de São Paulo - Brasil

Novembro - 1987 
Ao Gilberto, Gilbertinho, Fábio e ao que está para vir, pela compreensão $e$ esperança

\title{
Dedico
}

\author{
Aos meus pais \\ Messias, Elisa e Linda \\ ofereço
}

Aos meus irmãos, cunhados; cunhadas e sobrinhos

\section{Minha Homenagem}




\section{AGRADECIMENTOS}

- Ao Prof.Dr. Ronaldo Ivan Silveira, pela orientação, dedicaŗãc e paciência, durante todo o tempo de realização des te trabalho, sem as quais ele teria sido impossivel.

- Ao Engo Agrônomo Aracynio Tortolero Araujo, pelo apoio e estimulo.

- Ao Engo Agrônomo Carlos Alberto Oliveira de Matos, pela amizade e auxílio nas análises estatísticas e gráficos.

- Ao Prof. Artur Eduardo P. Toledo pela versão do resumo pa ra. o inglês.

- À Profa Elisa Daniel Barbosa, pela revisão dos textos.

- À senhora Nelci Teixeira Maniero, pela datilografia.

- À Escola Superior de Agronomia de Paraguaçu Paulista, pelo apoio e incentivo.

- À Escola Superior de Agricultura "Luiz de Queiroz", por tudo que foi oferecido durante meus estudos.

- À CAPES - Coordenação de Aperfeiçoamento de Pessoal de Ní vel Superior, pela concessão da bolsa de estudos, para a realização do curso.

- A todos os colegas e professores do curso, pelos valiosos ensinamentos. 
- A todos que, de uma forma ou de outra, concorreram para a realização deste trabalho.

- E a DEUS, por tudo. 
ÍNDICE

Página

RESUMO

SUMMARY

1. INTRODUÇÃ̃o $\ldots \ldots \ldots \ldots \ldots \ldots \ldots \ldots \ldots \ldots \ldots \ldots \ldots \ldots \ldots \ldots \ldots \ldots$

2. REVISÃD DA LITERATURA $\ldots \ldots \ldots \ldots \ldots \ldots \ldots \ldots \ldots \ldots$

2.1. o potássio no solo $\ldots \ldots \ldots \ldots \ldots \ldots \ldots \ldots, 4$

2.2. 0 equilibrio do potássio no solo $\ldots \ldots \ldots \ldots$

2.3. 0 potássio fixado $\ldots \ldots \ldots \ldots \ldots \ldots \ldots \ldots$. 6

2.3.1. Aspectos gerais da fixação ...... 6

2.3.2. Fixação e liberação do potássio .... 11

2.3.3. Influência da secagem e umedecimento na fixação $\ldots \ldots \ldots \ldots \ldots \ldots \ldots$ ' 13

2.3.4. Influência do tempo e da conçentração na fixação $\ldots \ldots \ldots \ldots \ldots \ldots \ldots . .16$

2.3.5. Influência do $\mathrm{pH}$ na fixação ...... 17

2.3.6. Efeito da CTC na fixação ......... 19

2.3.7. A influência de outros elementos na fixação $\ldots \ldots \ldots \ldots \ldots \ldots \ldots \ldots \ldots \ldots$

3. MATERIAIS E MÉTOdOS $\ldots \ldots \ldots \ldots \ldots \ldots \ldots \ldots \ldots . \ldots \ldots$

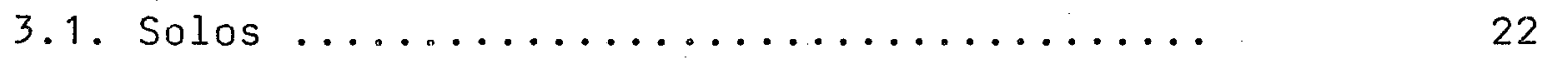

3.2. Determinação das características físicas e quimicas das amostras $\ldots \ldots \ldots \ldots \ldots \ldots$. 
3.2.1. Análise granulométrica ......... 26

3.2.2. Análise química de fertilidade das amostras $\ldots \ldots \ldots \ldots \ldots \ldots \ldots \ldots \ldots$

3.3. Análise mineralógica da fração argila .... 29

3.3.1. Reconhecimento dos minerais de argi ' 1 a $\ldots \ldots \ldots \ldots \ldots \ldots \ldots \ldots \ldots \ldots \ldots \ldots \ldots \ldots \ldots \ldots \ldots$

3.4. Determinaçãu da capacidade de fixação de

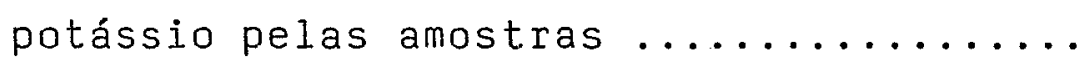

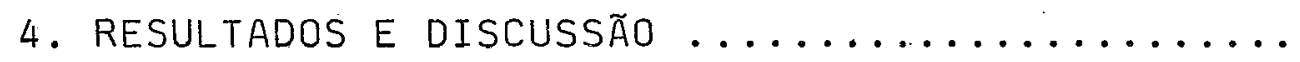
40

4.1. Efeito na fixação de potássio por doses crescentes de minério vermiculitico de Piaui (A) nas amostras dos solos Latossolo Vermelho Escuro-fase arenosa e Podzolizado de Lins e Marila-variação Lins ..........

4.2. Efeito na fixação de potássio causado por doses crescentes de minério vermiculitico de Catalão (B), nas amostras dos solos Latossolo Vermelho Escuro-fase arenosa e Podzolizado de Lins e Marília-variação Lins.

4.3. Influência do teor e da natureza de argila

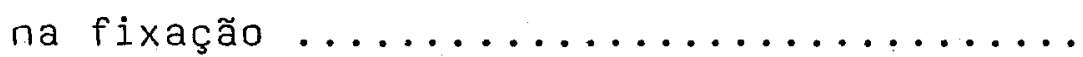

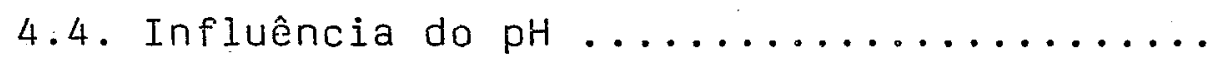

4.5. Efeito do cempo de contato entre o ín po-

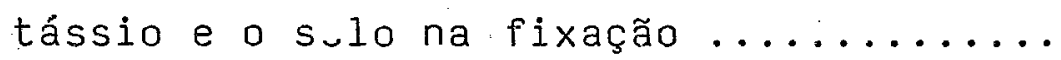


4.6. Efeito da quantidade de potássio adicionado na $f i x a c ̧ a a_{0} \ldots \ldots \ldots \ldots \ldots \ldots \ldots \ldots \ldots \ldots$

4.7. Influência da umidade e secagem na fixação. 62

5. CONCLUSÕES $\ldots \ldots \ldots \ldots \ldots \ldots \ldots \ldots \ldots \ldots \ldots \ldots \ldots \ldots \ldots \ldots$

LITERATURA CITADA $\ldots \ldots \ldots \ldots \ldots \ldots \ldots \ldots \ldots \ldots \ldots \ldots \ldots \ldots$ 
vii.

LISTA DE TABELAS

Página

1 - Localização e classificação dos solos a nível de grande grupo $\ldots \ldots \ldots \ldots \ldots \ldots \ldots$

2 - Quantidades de solo e minérios vermiculiticos nas amostras $\ldots \ldots \ldots \ldots \ldots \ldots \ldots$

3 - Análise granulométrica das amostras ......

4 - Caracteristicas quimicas das amostras de so

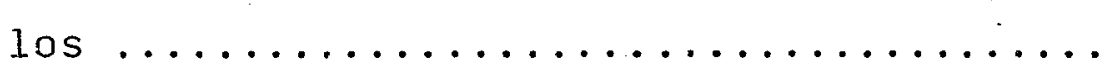

5 - Alguns minerais de argila e seus espaçamen-

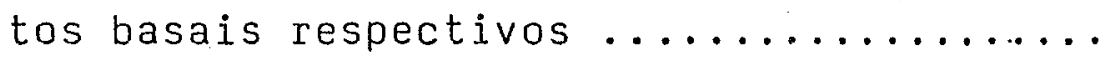

6 - Análise mineralógica da fração argila das amostras $\ldots \ldots \ldots \ldots \ldots \ldots \ldots \ldots \ldots \ldots \ldots \ldots \ldots \ldots \ldots \ldots \ldots$

7 - Resultados do ensaio de fixação de potássio obtidos da incubação do solo Latossolo Verme Tho Escuro-fase arenosa e quantidades variáveis de minério vermiculitico de Piauí (A) com dois níveis de potássio aos 10 e 20 dias. 
8 - Resultados do ensaio de fixação de potássio ob tidus da iriclbaçõo do solo podzoljzaco Lins e Marilia, variação Lins e quantidades variáveis de minério vermiculítico de piauí $(A), \quad$ com dois niveis de potássio aos 10 e 20 dias .....

9 - Análise de variância para a porcentagem de $k$ fixado pelas amostras com doses crescentes de minério vermiculitico Piaui (A) $\ldots \ldots \ldots \ldots \ldots$

10 - Resultados do ensaio de fixação de potássio ob tidos da incubação do solo Latossolo Vermelho Escuro-fase arenosa e quantidades variáveís de minério vermiculitico de Catalão ( $B$ ) com dois niveis de potássio aos 10 e 20 dias ..........

11 - Resultados do ensaio de fixação de potássio ob tidos da incubação do solo Podzolizado Lins e Marilia, variação Lins e quantidades variáveis de minério vermiculítico de Catalão (B), com dois niveis de potássio aos 10 e 20 dias ..... 
ix.

Página

12 - Análise de variância para a porcentagem de $K$ fixado pelas amostras com doses crescentes de minério vermiculítico Catalão: (B) ..........

13 - Porcentagens relativas da quantidade de $\mathrm{k}$ fixado pelos tratamentos aos 10 dias de incubação quando comparadas com os tratamentos correspondentes aos 20 dias de incubação, designados como indice $100 \ldots \ldots \ldots \ldots \ldots \ldots$ 
LISTA DE FIGURAS

Página

1 - Difratograma de raio-X da fração argila da amostra 09 (minério vermiculitico de Piauí) ........

2 - Difratograma de raio-X da fração argila da amostra 17 (minério vermiculitico de Catalão) ......

3 - Difratogramas de raio-X da fração argila da amostra 01 (Solo latossolo Vermelho Escuro-fase areno

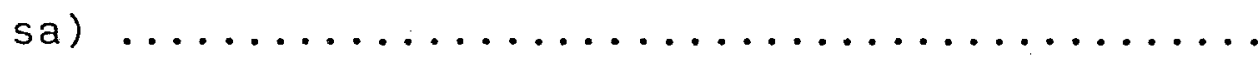

4 - Difratogramas de raio-X da fração argila da amostra 18 (Solo Podzolizado Lins Marilia-variação Lins

5 - Curvas de fixação de K para o solo Podzolizado com doses crescentes de minério vermiculitico de Piauí.

6 - Curvas de fixação de K para o solo Latossolo com doses crescentes de minério vermiculitico de Piauí.

7 - Curvas de fixação de K para o solo Podzolizado com doses crescentes de minério vermiculitico de Cata-

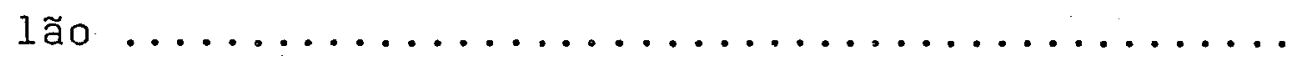

8 - Curvas de fixação de K para o solo Latossolo com doses crescentes de minério vermiculitico de Cata

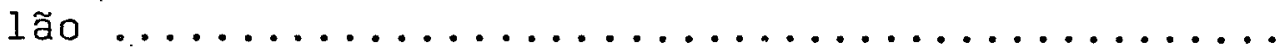


ESTUDO DO COMPORTAMENTO DO POTÁSSIO EM SOLOS QUE RECEBERAM QUANTIDADES VARIÁVEIS DE MINÉRIOS VERMICULÍTICOS

Candidata: MARIENE ESTEVÃ̆ MAPCHETTI Orientador: Ronaldo Ivan Silveira

\section{RESUMO}

A presente pesquisa foi desenvolvida no laborató rio de Solos da Escola Superior de Agronomia de Paraguaçu Pau lista, SP e, teve por objetivo avaliar os efeitos da dose de po tássio aplicado, do teor de argila e do tempo de contato entre - ion potássio e o solo na fixação do potássio.

Determinou-se a influência de dois minérios vermiculiticos procedentes de Catalão-Goiás e Paulistânia-Piaui, na fixação de potássio em dois solos de textura arenosa, com alta lixiviação de potássio, provenientes do município de Paraguaçu Paulista, classifjcados como Latossolo Vermelho Escuro-fase are nosa e Podzolizado de Lins e Marilia-variação Lins.

As amostras de terra foram coletadas no horizonte Ap, secas ao ar e misturadas com quantidades crescentes dos minérios vermiculiticos que variaram de $1,25 \%$ a $25 \%$ e foram 
comparadas com o minério puro, incubados durante 10 e 20 dias, com doses de 50 e 100 ppm de potássio no solo.

Nàs ánostrás de tarra e nos mirérías vermiculí.. cos foram feitas análises mineralógicas e em todas as amostras as análises químicas e físicas.

Nas amostras, foi adicionado o potássio e incuba das, por 10 e 20 dias em frascos plásticos, tapados para evitar perda de umidade.

Os resultados da porcentagem de potássio fixado pelos tratamentos foram analisados estatisticamente e, feito o estudo das interações, as seguintes conclusões foram obtidas:

1. a minério vermiculitico de Piaui fixou uma maior quantidade de potássio do que o minério vermiculítico de Catalão.

2. O comportamento dos solos variaram com o miné rio vermiculitico usado, sendo que o solo Padzolizado de Lins e Marília-variação Lins, fixou mais potássio do que o Latossolo Vermelho Escuro-fase arenosa quando em mistura com o minério ver miculítico de Piaui e o Latossolo fixou mais quando em presença do minério vermiculítico de Catalão. 
3. A porcentagem de potássio fixada pelos solos aumentou com o acréscimo do porcentual do minério vermiculítico de Piauí, até adquirir valores próximos à porcentagem fixada pelo minério puro. Para o minério de Catalão a fixação não variou com a quantidade do minério adicionado.

4. Em todos os tratamentos, a quantidade e a por centagem fixada aumentou com o tempo de contato, sendo que cer ca de 70 \% ou mais da fixação ocorreu aos 10 dias de incubação para o minério vermiculítico de Piaui, para o minério de Catalão em torno de 40 a $70 \%$, o que mostra que o processo tendeu a estabilizar-se entre os períodos estudados de 10 e 20 dias.

5. Dentro de um mesmo tempo de incubação, o potássio fixado, aumentou com a dose de potássio adicionado (50 e $100 \mathrm{ppm}$ ), mas o porcentual fixado diminuiu, indicando a satu ração das amostras com o ion potássio.

Do exposto acima pode-se concluir que existe uma variação no comportamento dos minérios vermiculiticos em relação à fixação de potássio, provavelmente dependendo de sua or gem, composição e granulometria. 
THE STUDY OF THE BEHAVIOR OF POTASSIUM IN SOILS THAT RECEIVED DIFFERENT QUANTITIES OF VERMICULITIC MINERALS.

Candiciate: MARLENE ESTEVÄO MARCHETTI Adviser: Ronaldo Ivan Silveira

SUMMARY

The experiment was carried at the Laboratory of Soils of Agricultural College of Paraguaçu Paulista, SP. The objetive of this research was to study the effect of potassium levels added, clay amount and effect of time contact between po tassium ion and soil in the fixing of potassium.

It was evaluated the effect of two clays minerals the first from Catalão-Goiás and the other from Paulistânia Piaui, on the potassium fixing capacity of two sandy soils, yel low red Podzolic and dark red Latosol, both occuring in the Paraguaçu Paulista municipality.

Quantities varying from $1.25 \%$ to $25 \%$ (weight

basis) were throughly mixed with samples taken from the Ap horizon of the two soils. Two groups of treatments were prepa red, with an: application of soluble potassium one at the rate 
of 50 and the other at the rate of $100 \mathrm{ppm}$, and both were in cubated for two different periods, 10 and 20 days.

Both the soil samples and veimiculjtic minerals were analised according to their mineralogical characteristic. The chemical characteristic and the particle size distribution of the sample were also determined.

Potassium was addicionated and incubated for 10 and 20 days in closed plastic recipients, in order to avoid the loss of moisture.

The results obtained were statistically analyzed. The following conclusion were obtained.

1. The vermiculitic from Piaui showed a greater potassium fixing capacity than vermiculit from Catalão.

2. The behavior of solls differed according to the vermiculitic mineral that was added. The yellow red Podzolic fixed more potassium ions than the dark red Latosol, when it was mixed to vermiculitic mineral from piaui and the dark red Latosol fixed more when it was mixed to vermiculitic mineral from Catalão. 
3. The percentage of potassium fixed by the soils incresead with the percentage of vermiculitic from Piaui, approaching to the fixing capacity of the pure clay mineral. The lermicuitis für Cataião dia not show any variation according to the amount of clay added.

4. The amount and the percentage of fixed potassium increased with the time of incubation of the treatments.

5. For a given incubation period ( 10 a 20 days) the amount of potassium fixed (ppm) increased with the rate of potassium added, but the fixed potassium percentage decreased, indicating thar the samples were probably satured with the potassium ions.

The ability of fixing potassium of vermiculite minerals varied according to their origin, composition and the particle sizes. 


\section{INTRODUÇÃO}

o potássio é considerado o segundo elemento em concentração na matéria seca das plantas, quando se conside ram os nutrientes minerais essenciais.

As produções mais altas são obtidas, quando as exigências de potássio e dos demais nutrientes da planta são totalmente atendidas.

Com o crescente aumento populacional há uma maior demanda de alimentos, fibra e energia e, então a procura de uma produção máxima deve ser o principal objetivo. Para que esta meta seja atingida, a adubação potássica terá um papel cada vez mais importante $e$, portanto devemos nos aprimorar afim de minimizar as perdas de potássio por lixiviação. 
Dentre os nutrientes o potássio é o segundo mais utilizado no Brasil. o consumo de cloreto de potássio em 1985 foi de 1,7 milhão de tonelada, sendo esta demanda atendida irteirancrite por inposta̧̧ão do adubo. 0 Brosil constituise num dos maiores importadores mundiais de cloreto de potássio e, estima-se que este ano o Brasil aplicará cerca de US\$ 160 milhões nesta importação.

0 potássio tem muitas funções na bioquímica e fisiologia da planta. É um ativador enzimático e atua na abertura e fechamento dos estomatos, transporte de carboidra tos, transpiração, resistência a seca, geada e salinidade.

Nas partes vegetativas da planta produz uma maior área foliar, maior densidade de clorofila e maior suculência das folhas, sugerindo melhores condições para a fotossintese (BERINGER, 1982).

0 potássio tem sido há muito tempo considerado - elemento de qualidade em nutrição de plantas, pois aumenta - conteúdo de proteina bruta, maior reserva de carboidratos nas plantas, aumenta a produção de óleo, minerais e vitaminas, a qualidade física e a aparencia das frutas e verduras. 
Em vista do exposto, do alto consumo e da alta lixiviação e, aliado à existência de jazidas de minérios no Brasil, que pode ser utilizado no melhoramento de solos arenosos. com alta lixiviação, modificando suas condições fisi cas e químicas e, aumentando a retenção de potássio, foi rea. lizado o presente trabalho, em condições de laboratório, com o objetivo de estudar:

1. O efeito na fixação de potássio no solo, cau sado por doses crescentes de minérios vermiculíticos.

2. A diferença no comportamento, de dois minérios vermiculíticos na fixação. de potássio.

3. A influência do tempo de contato entre o" ion potássio e o solo, na fixação de potássio.

4. A correlação entre os teores de potássio adicionado e a fixação de potássio. 


\section{REVISÃO DE LITERATURA}

2.1. O potássio no solo

o potássio total no solo é encontrado em quatro formas de acordo com Ritchey (1979) citado por LOPES (1982), a saber: (a) potássio que ocorre como um componente estrutural de minerais tais como micas e feldspatos potássicos e, que se torna disponivel apenas quando estes minerais são decompostos; (b) potássio temporariamente "fixado" entre lâminas de argi las expansivas; (c) potássio facilmente trocável por um sal neutro, não tamponado e dá uma pequena quantidade de potássio presente na solução do solo.

De acordo com Black (1967), citado por BRAGA e YAMADA (1984), as diferentes forças com que o potássio se ad sorve aos minerais secundários do solo permitem classificá-10 quimicamente em não-trocável, trocável e solúvel em água. Des tes parâmetros, o $\mathrm{K}$ trocável, é o mais utilizado no estudo da fertilidade do solo. 
Goedert (1973), citado por LOPES (1982), diz ser - potássio total de um solo cosntituído, principalmente, pelo potássio estrutural ( 90 a $98 \%$ ); o potássio trocável nas dife rentes formas contribui para o potássio total com 2 a $8 \%$ e o potássio na solução do solo com 0,1 a $0,2 \%$.

Tisdale e Nelson (1975), citados por LOPES (1982) classificam as formas de potássio existentes no solo em potás sio não disponivel; potássio prontamente disponível. O potássio não disponível refere-se ao potássio estrutural dos minerais primários não intemperizados ou ligeiramente intemperiza dos, minerais secundários (ilita, vermiculita, clorita) e minerais interestratificados em que dois ou mais destes tipos de minerais secundários, ocorrem em arranjamento mais ou menos ao acaso, na mesma partícula. o potássio lentamente disponivel refere-se àquele potássio disponível (trocável ou em solução), que é "fixado" ou retido entre as camadas de certas argilas expansivas.

\subsection{O equilíbrio do potássio no solo}

A relação entre o potássio liberado e o potás sio fixado, resultando num equilibrio de várias formas de potássio no solo, tem recebido atenção de muitos pesquisadores.o estágio de intemperização,tipos e quantidades de minerais pri mários e secundários que contém potássio,tem sido sugerido co 
mo fatores que afetam, o nivel de equilibrio de potássio (DowDY e HUTCHESON, 1963).

Nos scles, ä naior parte do putássio disponivel é retido na forma trocável no complexo de troca. A atividade dos ions potássio na solução do solo depende primeiramente da quantia de potássio no complexo de troca. Existe uma ampla evi dência, mostrando o equilibrio do solo. Existe, também umi equi líbrio entre o potássio trocável e o potássio fixado, sendo es te estabelecido mais lentamente. Então a proporção de potás sio no estado fixado pode aumentar pelas aplicações repetidas de fertilizantes potássicos e ser reduzido pelos cultivos con tínuos, devido a tendência para se manter o equilibrio (MAT THEWS E BECKETT, 1962).

Segundo DENNIS e ELLIS (1962), a fixação e a li beração de potássio no solo parece ser um processo de equilí brio. Em experimentos realizados, a fixação aumentou com o au mento de potássio solúvel.

2.3. D potássio fixado.

2.3.1. Aspectos gerais da fixação

Tem-se verificado, em numerosos solos, que uma parte do potássio adicionado na forma de um sal solúvel não é recuperada por extração com reagentes usuais de troca catiôni- 
ca. Diz-se, neste caso, que o potássio é fixado ou que ocorre o fenômeno de fixação de potássio (GAMA, 1961).

A fixação do potássio tem recebido consjderável atenção, devido a importância da disponibilidade do potássio pa ra as plantas. A fixação do potássio é muito influenciada pela mineralogia da argịla, e é favorecido pela ocorrência de vermiculita, micas hidratadas e montmorilonitas (ARIFIN et alii, 1973; CARSON E DIXON, 1972; DEMUMBRUM, 1958; DEMUMBRUM e HOOVER, 1958; MCLEAN E BRYDON, 1971).

A fixação de potássio é um fenômeno comum, e a intensidade depende da quantidade e da natureza das argilas pre sentes nos solos (DOWDY e HUTCHESON, 1963; BRADY, (1983) e tam bém da umidade do solo (DEMUMBRUM e. HOOVER, 1958).

A fixação de potássio nos solos e a relação com a mineralogia de argila tem sido objeto de numerosas investigações (MCLEAN, 1963 e WELTE e NIEDERBUdDE, 1965). A ligação da fixação do potássio tem sido estabelecida com um mineral de argila, a vermiculita (DENNIS e ROSCOE, 1962).

De acordo com BRADY (1983), a vermiculita nos so los fixa uma quantia considerável de potássio. RAFAHI (1980)con clui que existe uma correlação positiva entre o potássio fixado e o conteúdo de vermiculita. 
BARSHAD (1954), estudando o mecanismo da fixa ção do potássio nos solos, verificou que uma grande quantia de potássio era fixado pela vermiculita.

Rich (1968), citado por BITTENCOURT e SAKAI (1975) concluiu que tanto a vermiculita como a mica apresentam cargas de alta seletividade para $0 \mathrm{~K} \mathrm{e}$, dependendo das condi ções podem fixar o elemento com maior ou menor intensidade.

Van DER MAREL (1954), em trabalhos realizados em solos de Dutch, verificou que as camadas expandidas dos silica tos, cujo espaçamento basal era de 15 ou $16^{\circ} \mathrm{A}$, foram os respon sáveis pela fixação de potássio nos solos.

ATtOE (1948) em solos de Wisconsi, observou que a fixação é comum, principalmente se houvesse excesso de potás sio na solução do solo. STANFORD et alii (1948), fez observações similares.

DENIS E e ELLIS (1962), estudaram a influência de diferentes níveis de potássio adicionado no equilibrio do potássio na solução do soló, potássio trocável e potássio fixa do pela vermiculita e, concluiram que as argilas do tipo $2: 1$ fixam potássio entre suas lâminas em secagem. 
Em presença de vermiculita, de ilita e de outros minerais do tipo $2: 1$, o potássio de alguns fertilizantes como o cloreto de potássio, torna-se fixado por estes colóides. Os ions potássio se encaixam nas intercamadas das unidacies cristalo gráficas destas argilas expansivas e, tornam-se parte integran te do cristal. Desta forma, este potássio não se acha prontamente assimilável pelos vegetais, atuando assim como um reservatório de potássio assimilável, devido o equilibrio com as ou tras formas (BRADY, 198氵).

ARIFIN et alii (1973), estudando a fixação de potássio, em diversas argilas, conclui que todas elas mostra ram capacidade para fixar o potássio. A quantidade fixada foi positivamente correlacionada com a quantidade de potássio apli cada.

Em pesquisas realizadas em laboratório, Amu (1969) citado por BARBER (1979), encontrou vários solos de Kericho, no Kenya, que fixou $50 \%$ e ocasionalmente $100 \%$ do potássio aplicado para $100 \mathrm{mg} \mathrm{kg}{ }^{-1}$.

DEMUMBRUM (1958), em trabalhos realizados "em Mississipi, verificou a presença suficente de vermiculita para causar a fixação de potássio nestes solos. 
Em experimentos realizados, RICHARDS e MCLEAN (1963), concluiram que a vermiculita tratada com potássio fixou mais que outros minerais de argila, sendo que houve varia ções nos tratamentos secos ao ar e em estufas, com a adição de 10 meq $K, 62$ e $71 \%$ do potássio adicionado foi fixado, respec tivamente, para tratamentos secos ao ar e em estufas.

DEMUMBRUM e HOOVER (1958) relataram que a vermiculita seca, em estufú, causou quase 100 \% de fixação para 10 meq $\mathrm{K} / 100 \mathrm{~g}$ argila.

Existe muita controvérsia, na literatura, sobre o efeito que a fixação do potássio exerce no aproveitamento do potássio no solo. Em muitos casos este fenômeno tem sido vís to com certo jnteresse devido o efeito causado na redução da disponibilidade para as culturas do potássio aplicado como fertilizantes. Entretanto, BRAY e DE TURK (1938) e outros, consideraram esta fixação benéfica, porque o potássio fixado não está sujeito a lixiviação e pode tornar-se disponivel às plantas sob condições adequadas.

ATTOE (1948), considerou que o potássio fixado serve como um reservatório de potássio para as plantas, e que esta fixação serve para evitar perdas por lixiviação e previnir o consumo de luxo pelas plantas. 
De acordo com AHMAD e DAVIS (1970), a extensão da fixação e a distribuição do potássio disponivel entre a for ma trocável e solúvel é importante, pois afeta a eficiência do uso do potássio aplicado como fertilizante.

\subsubsection{Fixação e liberação do potássio}

A fixação de potássio pelos solos tem recebido considerável atenção, dévido seus efeicos na disponibilidade do potássio para as plantas e, tem sido demonstrado que a fixação e a liberação do potássio estão diretamente relacionadas com a mineralogja de argila dos solos. Segundo JOFFE e LEVINE (1946), desde que a fixaçăo do potássio em solos é um fenômeno comum,o problema da liberação do elemento disponivel é também de grande importância.

Segundo RICHARDS e MCLEAN (1963), o mineral de argila pode variar consideravelmente na extensão da fixação e liberação de potássio, de acordo com as condições sob as quais foi desenvolvido.

A magnitude da fixação e da liberação de potássio parece estar diretamente relacionado com a mineralogia da argila. (DOWDY e HUTCHESON, 1963). 
REITEMEIR (1951), sugeriu que a fixação ou a lí beração do potássio pode ocorrer em solos secos. Geralmente, a fixação ocorre, quando os niveis iniciais de potássio trocável são altos e a liberação ocorre quando os niveis iniciais são baixos.

Cook e Hutcheson (1960), citados por DOWDY e HUTCHESON (1063), em estudos realizados em seis amostras de so los seco ao ar, mostraram que houve liberação de potássio, quan do o solo foi lavado com solução neutra de acetato de amônio $1 \mathrm{~N}$ e o nivel de potássio trocável menor que $0,5 \mathrm{meq} \mathrm{K} / 100 \mathrm{~g}$ so10, e que houve a fixação quando o nivel de potássio trocável era maior que 0,5 meq $K / 100 \mathrm{~g}$ solo.

BRAY e DE TURK (1938), em pesquisas realizadas com solos de Illinois, onde o teor de potássio trocável era baixo, concluiu que poderia haver fixaçăo de potássio original ou adicionada, e que os solos, cujos teores de potássio trocável eram altos, poderia haver liberação do potássio.

Resultados discordantes foram obtidos por SCOTT et alii (1957). Eles mostraram que para ocorrer a fixação do potássio era necessário um alto nivel do mesmo, e que com um nivel inicial de potássio trocável baixo houve a liberação do elemento. 
Com experimentos realizados em vasos, Bartholomeu e Jansen (1931), citados por JOFFE e LEVINE (1946), observa ram que parte do potássio não disponivel, foi mais tarde utilizados pelas plantas.

0 conteúdo de potássio trocável, fixação, o teor de potássio nas culturas e a porcentagen de recuperado foi estu dado em cultura de cevada por ATTOE (1948). Este concluiu que cerca de $76 \%$ a $98 \%$ do potássio aplicado foi recuperado pelas culturas, durante dois anos de cultivo, embora uma considerável quantia de potássio tenha sido fixado. Com base nestes resulta dos, concluiu ser o potássio fixado um processo não tatalmente prejudicial, embora ocorra uma redução temporária no potássio disponível. Este potássio fixado seria então considerado como um reservatório.

2.3.3. Influência da secagen e umedecimento na fixação

Tem sido estabelecido por diversos autores que o processo de fixação do potássio no solo varia de acordo com o secamento e umedecimento do solo. VOLK (1934), concluiu que embora a fixação possa acontecer em solo úmido, ela dá-se sobretú do em condições de secagem. REITEMEIR (1951), sugeriu que a fixação e a liberação de potássio pode ocorrer em solos secos. 
RANEY e HOOVER (1946), estudaram a fixação do po tássio em solos de Susguhama, Mississipi e observaram que a fixação foi incrementada com o secamento dos solos, e que altacon centração de potássio na soluçãa do solo favoreceu a fixaçăo.

De acordo com WEAR e WHITE (1951), é um assunto controvertido se o secamento do solo ou do mineral de argila é necessário ou não para que haja a fixação. Entretanto, numerosos trabalham mostram que pequenas quantias de potássio são fixadas em solos ou mineral de argilas umedecidos. A quantia de potássio fixada sob esta condição é pequena, comparado com a quantidade fixada quando o complexo de troca é saturado com potássio e o solo ou mineral de argila é seco:

Em experimentos realizados por SCOTT et alii (1957), observaram que quando uma quantidade média de cloreto de potássio foi adicionada, ocorreu a fixação ou a liberação do potássio, dependendo do nivel de umidade do solo e, conclujuque para estabelecimento de um equilíbrio de potássio no solo é importante definir o grau de secamento do mesmo. Isto indicou en tão que um solo pode ter diferenças no equilibrio sobre diferen tes condições de umidade.

Em solos de Ontário, MATHEUS e SHERRELL (1960), notaram que a constante de equilibrio era de $1,11 \pm 0,12 \%$ de potássio sacurando o complexo de troca sem considerar o tjpo de 
solo. Observaram que solos secos fixaram potássio, se o percen tual de saturação em potássio era maior de 1,11 e liberaram șe o percentual de saturação era menor do que 1,11 .

Numerosos trabalhos têm associado a fixação e a liberação de potássio para diferentes níveis de umidade com a presença de certos minerais de argila. DEMUMBRUM e HOOVER (1958), relataram que a vermiculita fixa grande quantidade de potássio adicionado sob condições de umidade, e que teve uma fixação adi cional com o secamento.

MARTINI e SUAREZ (1977), trabalharam com ciclos sucessivos de umidade e secamento, em solos da Costa Rica, concluiram que quando os solos foram incubados sob contínua condição de umidade favoreceu a fixação do potássio trocável, e que quando incubados sob ciclos de umidade e seciamento, resultou nu ma liberação do potássio não trocável.

A secagem do solo, mesmo em temperatura inferjor a $100^{\circ} \mathrm{C}$, pode intensificar a fixação pelo aumento da concentração de potássio, na solução do solo em torno da particula de a r. gila MIELNICZUK (1982). 
2.3.4. Influência do tempo e da concentração na fixação

Em experimentos conduzidos por Von AMBERGER et alii (1974), em vasos, por um período de três aros, foi evidenciado a influência do tempo na quantidade de potássio fixado. Conclui ram que a maior parte do potássio adicionado foi fixado imediatamente dentro de poucas semanas após a aplicação. A quantidade de potássio trocável não aumentou, marcadamente, até que uma aplicação mais alta de pútássio fosse realizada, e o potássio trocável aumentou significativamence com uma redução na fixação.

AHMAD e DAVIS (1970), conduziram pesquisas com solos de Trinidad e verificaram que os valores de potássio fixa do flutuou de mês para mês, mas a análise de variância indicou que em ambos os tempos a concentração de potássio adicionada foi altamente significativa, causando a fixação. Apesar da fixação aumentar com a concentração, em percentual, a fixação teve tendência para decrescer com o aumento da concentração.

Segundo BARBER (1979), todos os solos mostram una tendência de aumento na quantidade de potássio fixado com o incremento na taxa de potássio aplicado e a fixação aumentou com o aumento no conteúdo de argila dos solos. 


\subsubsection{Influência do pH na fixação}

$\mathrm{Na}$ literatura, encontra-se relatos de que a adi ção de calcário no solo estimula a fixação do potássio. Macintire et alii (1936), citado por JOFFE e LEVINE (1947), verifi-.. cando o efeito do cálcio'e do magnésio, conluiram que a adição de calcário aumentou a fixação.

HARRIS (1937), relatou que o óxido de cálcio hi dratado aumentou a quantidade de potássio fixada, e além disso uma maior fixação ocorreu com valores de pH mais alto. Observações semelhantes foram feitas por Gilligan (1938), citado por JOFFE e LEVINE (9147), onde a Fixação de potássio aumentou com - aumento da saturação em cálcio e aumento do pH.

AYRES (1941), em estudos realizados em solos da Costa Hilo, Havai, mostrou que mais potássio entram para o com plexo de troca com o aumento do pH, então mais potássio é disponível para a fixação e consequentemente mais potássio é fixą do.

Estudando o potássio em três solos do Estado de São Paulo BITTENCOURT e SAKAI (1975), concluiram que a adição de $\mathrm{CaCl}_{2}$ ou de $\mathrm{Ca}(\mathrm{OH})_{2}$ aos solos de uma maneira não uniforme ocasiona uma maior liberação de potássio, e notaram um efeito mais pronunciado do $\mathrm{pH}$ sobre o deslocamento de potássio das 
formas trocáveis do que, propriamente, do poder de substituição do cálcio.

De acordo com MIELNICZUCK (1982: , os solos âci dos, mesmo com minerais do tipo $2: 1$, fixam menos potássio devido à formação de depósitos de hidróxidos de $A l$ ou Fe entre as camadas, o que impede até certo ponto o fechamento destas. Esta conclusão confirma os resultados obtidos por STANFORD (1947), on de observou que a presença de $\mathrm{H}, \mathrm{Fe}$ e $\mathrm{Al}$ em solos ácidos, sob condições de umidade, diminuia a fixação de potássio.

A presença de hidróxido de aluminio ou ferro nas intercamadas poderá inibir a fixação de potássio pelas argilas do solo, mas poderá permitir a remoção de potássio das posições das cunhas por cations de tamanho semelhante como $\mathrm{ONH}_{4}$ (RICH ; 1960).

Duchanfour (1970), citado por RAFAHI (1980): e BRADY (1974), mostrou que uma elevação no pH e a abundância de calcário nos solos, favorecia a fixação. 
2.3.6. Efeito da CTC na fixação

Há uma certa evidência da influência da CTC na fixação do potássio. Truog e Jones (1938), citados por JOFFE e LEVINE (1947), relataram que o decréscimo na capacidade de troca catiônica foi equivalente à quantia de potássio fixado. Entretanto, isto não foi evidenciado pelos trabalhos de JOFFE e KOLODNY (1938), que encontraram, em geral, uma redução na capacidade de troca, quando a fixação ocorreu, mas não notaram una equivalência entre este decréscimo e a fixação.

ARIFIN et alii (1973), en pesquisas realizadas em diversos solos dos Estados Unidos, estudando a capacidade de fixação das argìlas, onde a fixação variou de $i .135 \mathrm{mg} \mathrm{K} / 100 \mathrm{~g}$ até $2.225 \mathrm{mg} \mathrm{K} / 100 \mathrm{~g}$, concluiram que em alguns solos não houve correlação entre a fixação de potássio e a CTC, e que en outros solos a fixação foi duas ou três vezes maior do que a CTC, e em outros foi menor que a CTC. Então não pode com estes experimen tos estabelecer uma correlação entre fixação e crc.

AHMAD e DAVIS (1970), trabalhando com solos de Trinidad, concluiram que os solos começaram a fixar potássio pa ra uma concentração de potássio equjvalente a $3 \%$ da CTC, e isto não foi condizente com os resultados obtidos por Moss (1963), onde foi necessário $62 \%$ de saturação em potássio no complexo de troca para que houvesse a fixação. 
2.3.7. A influência de outros elementos na fixação

Tem sido muito destacado a influência de outros ions na fixação do potássio. É conhecida a afínidade dos ions potássio e $\mathrm{NH}_{4}$ no fenômeno da fixação estando, geralmente, estabelecido que estes ions são fixados pelo mesmo mecanismo. (REITMEIER, 1951; STANFORD e PIERRE, 1946; HANWAY et alii, 1957). A fixação prévia de $\mathrm{NH}_{4}$ pode contrariar ou mesino anular a fixa Ção de potássio. STANFORD e PIERRE (1946), em estudos realiza dos num solo franco-argilo-limoso, mostraram que as quantida des de potássio fixado ell amostras contendo niveis diferentes de amônio fixado, eram inversamence proporcionais a estes ní veis.

STANFORD E PIERRE (1947), trabalhando em solos de Iowa, encontraram correlação significativa entre a capacida de de fixação do íon potássio e do íon amônio em estado de umi dade. Barshad (1948), citado por WEAR e WHITE (1951), em seus experimentos mostrou que somente parte do potássio adsorvidope la vermiculita foi substituído pelo ín amônio.

DENNIS e ELLIS (1962), estudaram a fixação e o equilibrio de potássio pela vermicuite saturada com sódio e cálcio, e concluiram que o potássio solúvel em água foi muito grande e o potássio trocável menor para o sistema saturado com 
cálcio. Para um dado nivel de potássio, a quantidade de potás sio fixada foi muito maior, quando o cálcio foi o cation com plementar.

Foi demonstrado o efeito do ânion acomparihante na fixação do potássio. DE TURK et alii (1943) demonstraram que a fixação é incrementada, quando $\mathrm{KH}_{2} \mathrm{PO}_{4}$ era adicionada ao solo ao invés do KCl. Já AHMAD e DAVIS (1970), concluiram que $\therefore$ a fixação não foi significativamente afetada pelos anions Cl ou $\mathrm{PO}_{4}$, mas quando se usou $\mathrm{SO}_{4}$ e $\mathrm{NO}_{3}$ resultou comparativamente nu ma menor fixação. $\mathrm{O} \mathrm{KNO}_{3}$ foi associado com uma maior concentra ção de potássio solúvel em água.

Um outro elemento importante do solo, que tem mostrado efeitos na fixação do potássio, é a matéria orgânica. Gourley e Wanter (1939); Sturgis e Moore (1939) e Waliker e Stur gis (1940), citados por JOFFE e LEVINE (1947), conduziram expe rimentos em condições de campo e, concluiram que a matéria orgânica exerce efejto depressivo na fixação. Isto pode ser ex plicado com base na competição entre a matéria orgânica e a fração mineral dos solos para os cations trocáveis, neste caso o potássio. Devido a sua alta CTC, a maiéria orgânica compete e desvia uma quantia considerável de potássio da fração mineral. 


\section{MATERIAL E MÉTODOS}

Foram utilizadas amostras do horizonte superficial (Ap) de dois solos, do município de Paraguaçu Paulista, SP compreendido entre as coordenadas geográficas médias de: latị tude $22^{\circ} 24^{\prime} 53^{\prime} \mathrm{s}$, longitude $50^{\circ} 34^{\prime} 35^{\prime \prime W}$ e altitude $505 \mathrm{~m}$.

Os solos empregados foram, coletados, de uma camada de $0-20 \mathrm{~cm}$ de profundidade evitando-se obter amostras de áreas adubadas ou que tenha sido submetidas a outras práticas culturais.

As amostras foram secadas ao ar e passadas atra vés de peneiras de $2 \mathrm{~mm}$ de malha.

A classificação dos solos assim como sua locali zação são apresentadas na Tabela 1. 
Tabela 1 - Localização e classificação dos solos a nivel de grande grupo.

\begin{tabular}{|c|c|c|c|}
\hline $\begin{array}{l}\text { Número da } \\
\text { amostra }\end{array}$ & Localidade & Ordem & $\begin{array}{c}\text { Grande Grupo } \\
\text { (Comissão de Solos) }\end{array}$ \\
\hline 01 & Paraguaçu Pau & oxissol & Latossolo Vermelho \\
\hline & lista & & $\begin{array}{l}\text { Escuro fase arenosa } \\
\text { (LVE-fase arenosa) }\end{array}$ \\
\hline 18 & $\begin{array}{l}\text { Paraguaçu Paú, } \\
\text { lista }\end{array}$ & Alfissol & $\begin{array}{l}\text { Podzolizado de Lins } \\
\text { e Marilia, variação } \\
\text { Lins : }\end{array}$ \\
\hline
\end{tabular}

(SPLM-variação Lins)

Utilizou-se dois minérios de argila de grade $2: 1$, com predominância de vermiculita, um procedente do município de Catalão, estado de Goiás, e outro do município de Paulistania, estado do Piaui. Os minérios foram finamente moi dos e passados através de peneira 270 com $0,053 \mathrm{~mm}$ de abertura.

Os dois solos receberam quantidades variáveis dos minêrios veriniculiticos, obtendo-se amostras homogeneizadas para cada dosagem de solo e minério. Os teores das mistü ras acham-se na Tabela 2 . 
Tabela 2 - Quantidades de solo e minérios vermiculiticos nas amostras.

\begin{tabular}{|c|c|c|}
\hline $\begin{array}{l}\text { Número da } \\
\text { amostra }\end{array}$ & & $\begin{array}{c}\text { Solo e minério vermiculitico } \\
\%\end{array}$ \\
\hline 01 & $100 \%$ & LVE - fase arenosa \\
\hline 02 & $98,75 \%$ & LVE $+1,25 \%$ min. vermiculitico $A$ \\
\hline 03 & $97,50 \%$ & LVE + $2,50 \%$ min. vermiculitico $A$ \\
\hline 04 & $95,00 \%$ & LV $5+5,00 \%$ min. vermiculitico $A$ \\
\hline 05 & $90,00 \%$ & LVE $+10,00 \%$ min. vermiculitico $A$ \\
\hline 06 & $85,00 \%$ & LVE $+15,00 \%$ min. vermiculitico $A$ \\
\hline 07 & $80,00 \%$ & LVE $+20,00 \% \mathrm{~min}$. vermiculitico $A$ \\
\hline 08 & $75,00 \%$ & LVE $+25,00 \%$ min. vermiculitico $A$ \\
\hline 09 & $100 \%$ & minério vermiculitico $A$. \\
\hline 10 & $98,75 \%$ & LVE $+1,25 \%$ min. vermiculitico $B$ \\
\hline 11 & $97,50 \%$ & LVE $+2,50 \%$ min. vermiculitico $B$ \\
\hline 12 & $95,00 \%$ & LVE + 5,00\% min. vermiculitico $B$ \\
\hline 13 & $90,00 \%$ & LVE $+10,00 \%$ min. vermiculítico $B$ \\
\hline 14 & $85,00 \%$ & LVE $+15,00 \%$ min. vermiculitico $B$ \\
\hline 15 & $80,00 \%$ & LVE $+20,00 \%$ min. vermiculitico $B$ \\
\hline 16 & $75,00 \%$ & LVE $+25,00 \%$ min. vermiculitico $B$ \\
\hline 17 & $100 \%$ & minério vermiculitico $B$ \\
\hline 18 & $100 \%$ & SPLM - varação Lins \\
\hline 19 & $98,75 \%$ & SPLM $+1,25 \%$ min. vermiculitico \\
\hline 20 & $97,50 \%$ & SPLM $\div 2,50 \%$ min. vermiculitico \\
\hline Continua & & \\
\hline
\end{tabular}


Tabela 2 - Continuação

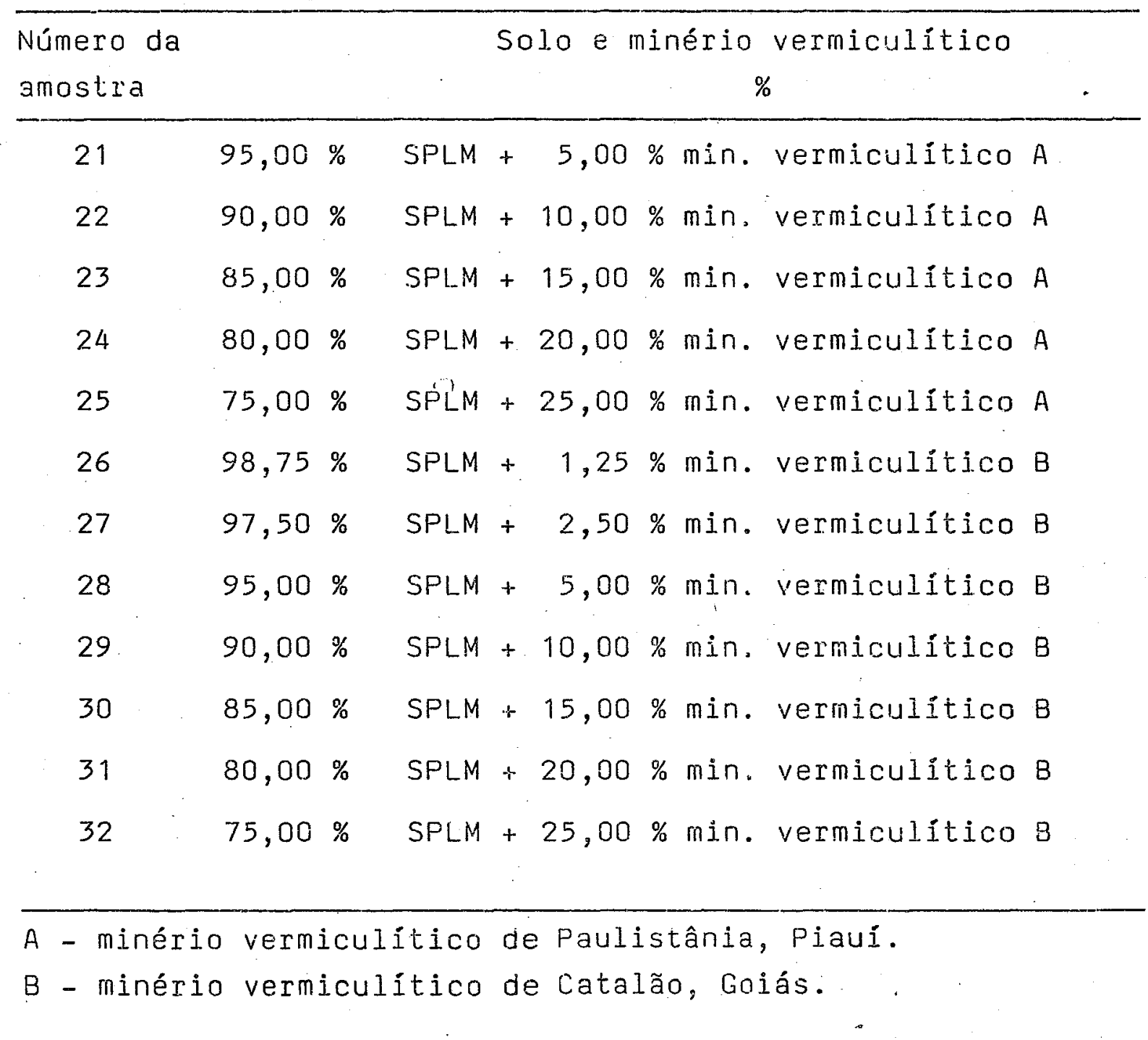




\subsection{Determinação das características físicas e químicas das} amostras

\subsubsection{Análise granulométrica}

As amostras de terra após receberem quantidades variáveis do minério foram analisadas no laboratórios de Solos do Departamento de Solos, Geologia e Fertilizantes da Escola Su perior de Agricultura "Luiz de Queiroz", sendo utilizado o méto do da pipeta descrito por KILMER e ALEXANDER (1949), empregan do-se como dispersante uma solução de hexametafosfato de sódio a $5 \%$. Os resultados são apresentados na Tabela 3.

3.2.2. Análise química das amostras para fins de fertilidade

A reação do solo $(\mathrm{pH})$ foj determinada potenciome tricamente em suspensão $1: 2,5$ de solo com $\mathrm{CaCl}_{2} \mathrm{O}, 01 \mathrm{M}$ e $\mathrm{H}_{2} \mathrm{O}$; - carbono orgânico pelo método de Walkley e Black, como descrito por JACKSON (1976); a matéria orgânica, pela multiplicação do ceor de carbono orgânico pelo fator 1,724; o fósforo solúvel pelo método colorimétrico após extração $\mathrm{com} \mathrm{H}_{2} \mathrm{SO}_{4} \mathrm{O}, 05 \mathrm{~N}$; O po tássio trocável foi determinado por fotometria de chama, após extração $\operatorname{com~H}_{2} \mathrm{SO}_{4} \mathrm{O}, 05 \mathrm{~N}$; o cálcio e o magnésio trocáveis por titulação com EDTA $0,01 \mathrm{M}$ após extração com KCl $1 \mathrm{~N}$; o alumínio trocável por titulação com $\mathrm{NaOH} 0,02 \mathrm{~N}$, após extração com KCl $1 \mathrm{~N}$; a acidez potencial por titulação cum $\mathrm{NaOH} 0,02 \mathrm{~N}$, após ex- 


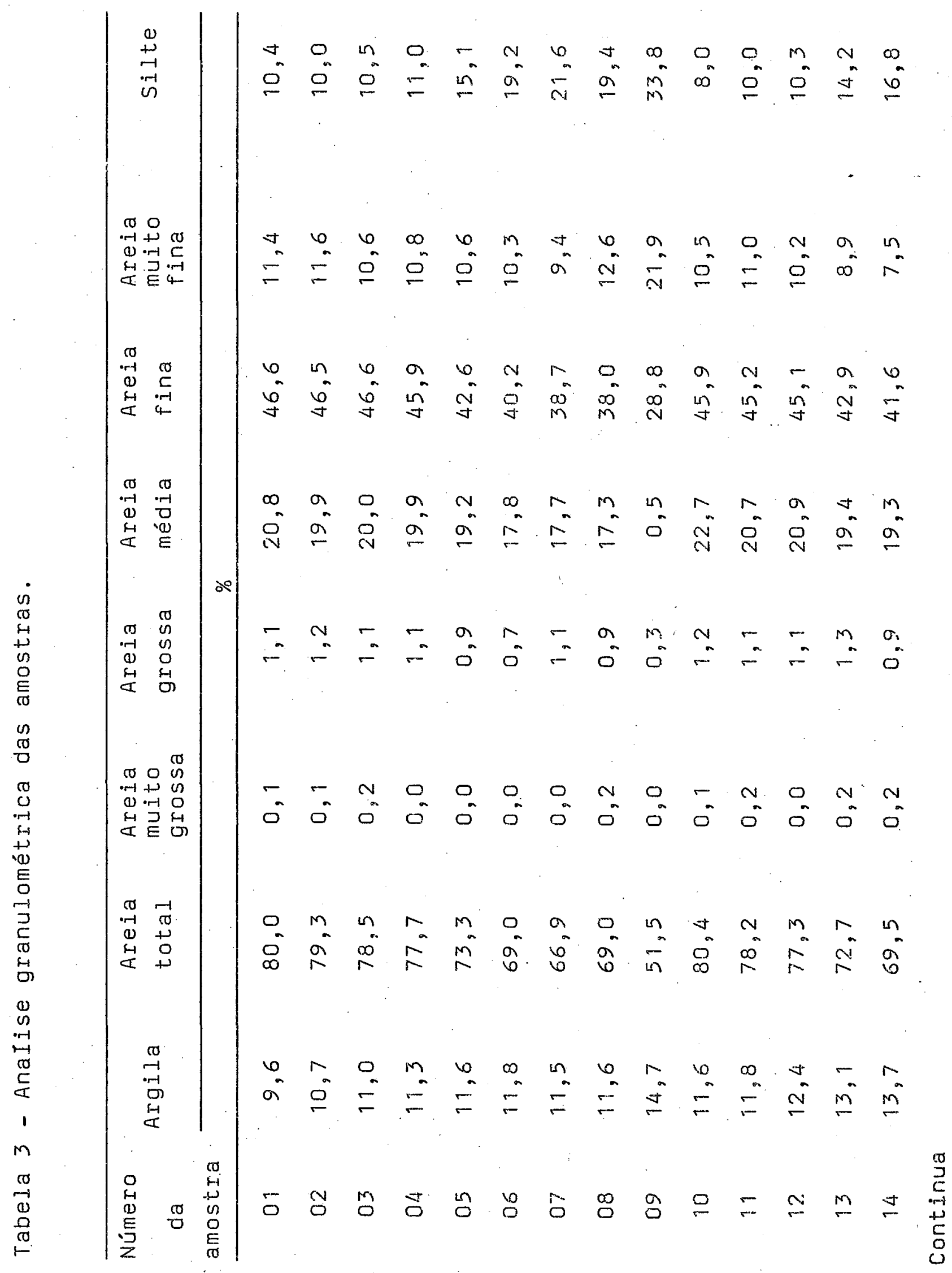




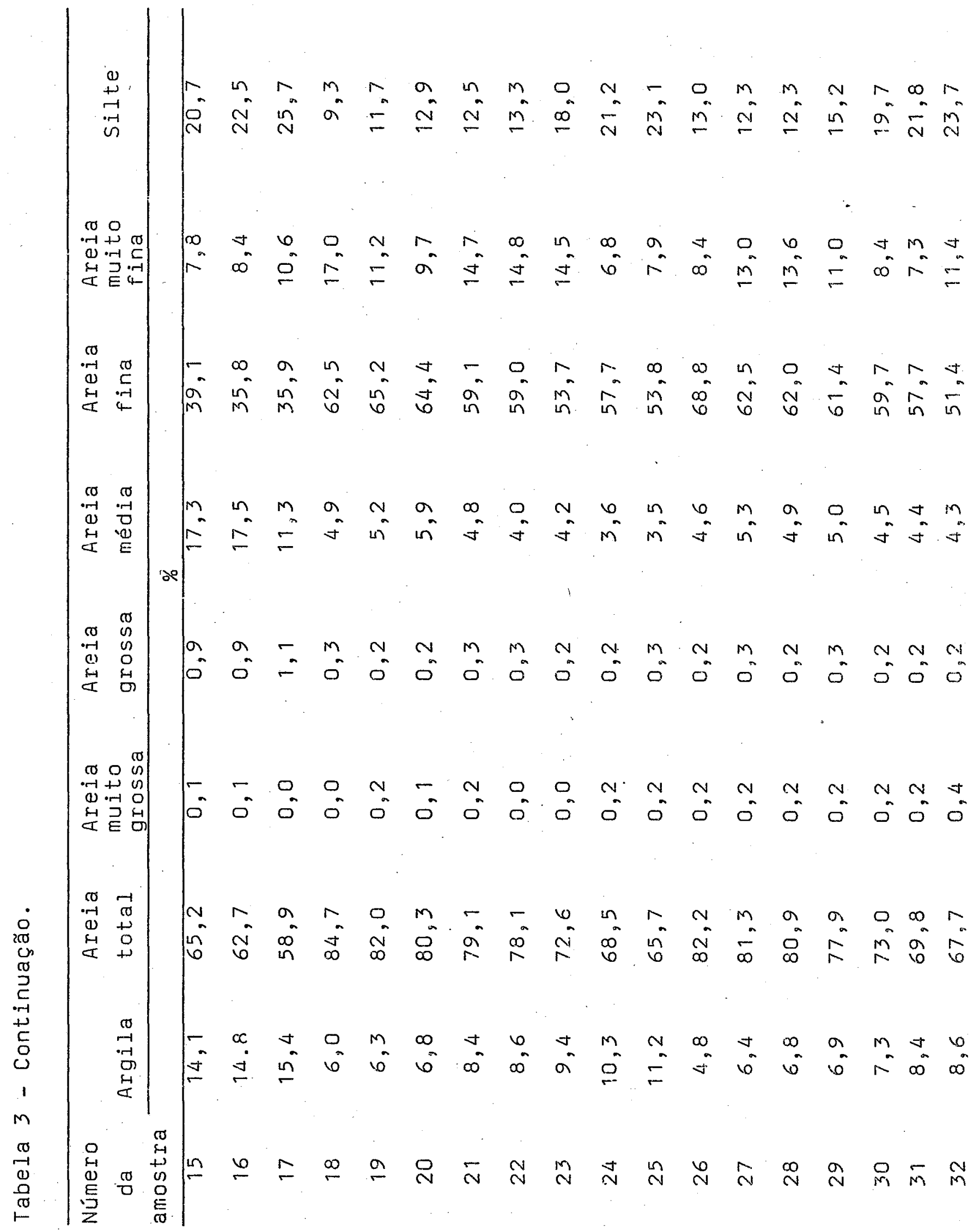


tração com acetato de cálcio $1 \mathrm{~N}, \mathrm{pH} 7,0$, de acordo com CATANI e JACINTHO (1974). A CTC ao pH 7,0 resultou da soma de cátions trocáveis (S) mais a acidez potencial $(H+A l)$. A saturação em bases pela divisão da soma de bases pela CTC, multiplicada por 100. Os resultados das análises são apresentadas na Tabela 4.

\subsection{Análise mineralógica da fração argila}

Na determinação mineralógỉca das argilas silica tadas das amostras de solo e dos minérios, procedeu-se conforme os métodos discutidos por JACKSON (1956).

Utilizou-se $30 \mathrm{~g}$ de TFSA da amostra, as quais foram submetidas a diferentes tratamentos até a obtenção das argilas cristalinas, em condição de serem analisadas por difratometria de raio- $x$.

Os tratamentos constaram da remoção dos sais solúveis e cations bivalentes trocáveis com uma solução tampão de acetato de sódio $1 \mathrm{~N} \mathrm{pH} \mathrm{5,0.} \mathrm{A} \mathrm{matéria} \mathrm{orgânica} \mathrm{e} \mathrm{os}$ óxidos de manganês livres foram removidos com peróxido de hidrogênio a 30 \% e para renoção dos óxidos de ferro livres empregou-se ditionito, citrato e bicarbonato de sódio que agem como redutor, quelante e tamīão, respectivamente. 


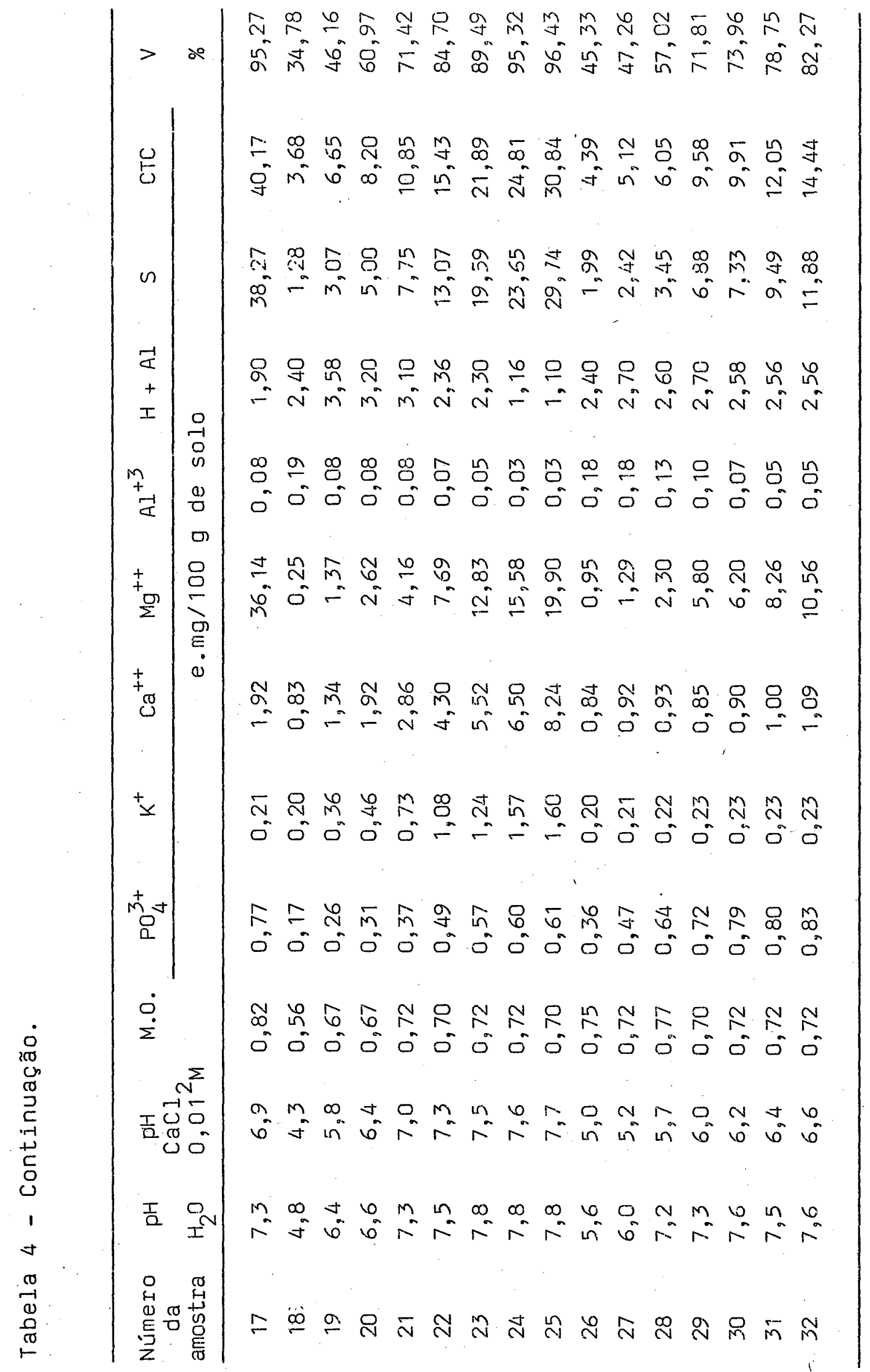


Para a dispersão e fracionamento das amostras separou-se as partículas maiores de $50 \mu$ (fração areia total) com um tamis de $0,05 \mathrm{~mm}$.de malha, litilizando como dispersante uma solução de carbonato de sódio pH 9,5. Deixou-se sedimen .. tar o silte de acordo com a Lei de Stokes (TEIXEIRA MENDES,1972) para depois sifonar a fração argila.

A fração argila obtida da amostra, foi saturada com potảssio ou magnésì para a análise qualitativa. Procedeuse a sucessivas lavagens com água, etanol e acetona até a eliminação total do cloreto. Posteriormente uma certa porção de argila saturada transferiu-se para lâminas de vidro no caso das amostras saturadas com potássio, foram aquecidas a $350^{\circ} \mathrm{C}$ e $550^{\circ} \mathrm{C}$ durante duas horas. As amostras saturadas com magnésio foram glicoladas (glicerol a 10 em solução alcoólica).

As lâminas saturadas com potássio a temperatura ambiente e as aquecidas $\left(350^{\circ} \mathrm{C}\right.$ e $\left.550^{\circ} \mathrm{C}\right)$, bem como as saturadas com magnésio (glicoladas), foram irradiadas no aparelho de raio-X tubo de cobalto no intervalo de $2-32^{\circ} 2 \theta$.

\subsubsection{Reconhecimento dos minerais de argila}

Uma vez obtidos no apareino de raio-X os difra. togramas das amostras, a temperatura ambiente, aquecidas e gli coladas, foi feita a jdentificação dos minerais componentes da 
fração argila mediante a determinação dos espaços interplanares (distância basal). Na Tabela 5 ilustram-se os valores ob tidos para alguns minerais de argila submetidos a diversos tratanentos de acordo às especificações de Lucas et alii (MEVES, 1968).

Tabela 5 - Alguns minerais de argila e seus espaçamentos basais respectivos.

$\because$

\begin{tabular}{|c|c|c|c|c|c|c|c|}
\hline \multirow{4}{*}{ Minerais } & \multicolumn{7}{|c|}{ Espaçamentos basais } \\
\hline & \multicolumn{3}{|c|}{ Saturação } & com $\mathrm{K}$ & \multirow{2}{*}{\multicolumn{2}{|c|}{$\begin{array}{l}\text { Satura- } \\
\text { ção com }\end{array}$}} & \multirow{2}{*}{$\begin{array}{l}\text { Outros es } \\
\text { paçamentos }\end{array}$} \\
\hline & \multirow{2}{*}{$\begin{array}{l}\text { Natural } \\
\left(25^{\circ} \mathrm{C}\right)\end{array}$} & \multicolumn{3}{|c|}{ Aquecido } & & & \\
\hline & & $350^{\circ}$ & & $550^{\circ} \mathrm{C}$ & \multicolumn{2}{|c|}{$\begin{array}{l}\text { Mg gli- } \\
\text { colada }\end{array}$} & $\begin{array}{l}\text { saturação } \\
\text { com K }\end{array}$ \\
\hline Caulinita & $7,2 \AA$ & 7,2 & $\AA$ & - & $T, 2$ & R & 3,5 \\
\hline Ilita & 10 & 10 & $R$ & $10 \AA$ & 10 & $\AA$ & $5,0-3,3$ \\
\hline \multicolumn{8}{|l|}{ Montmorilo- } \\
\hline nita & $12-14 \AA$ & 10 & $\AA$ & $10 \AA$ & 17 & Я & $5,1-3,05 \AA$ \\
\hline Vermiculita & $12-14 \AA$ & 10 & $\AA$ & $10 \AA$ & 14 & 8 & $5,0-3,2$ \\
\hline
\end{tabular}

Nas Figuras $1,2,3$ e 4 apresentam-se os difratogramas das amostras de argila e dos solos após ter sido sub metidas aos diversos tratamentos e irradiaçőes com raio-x. 


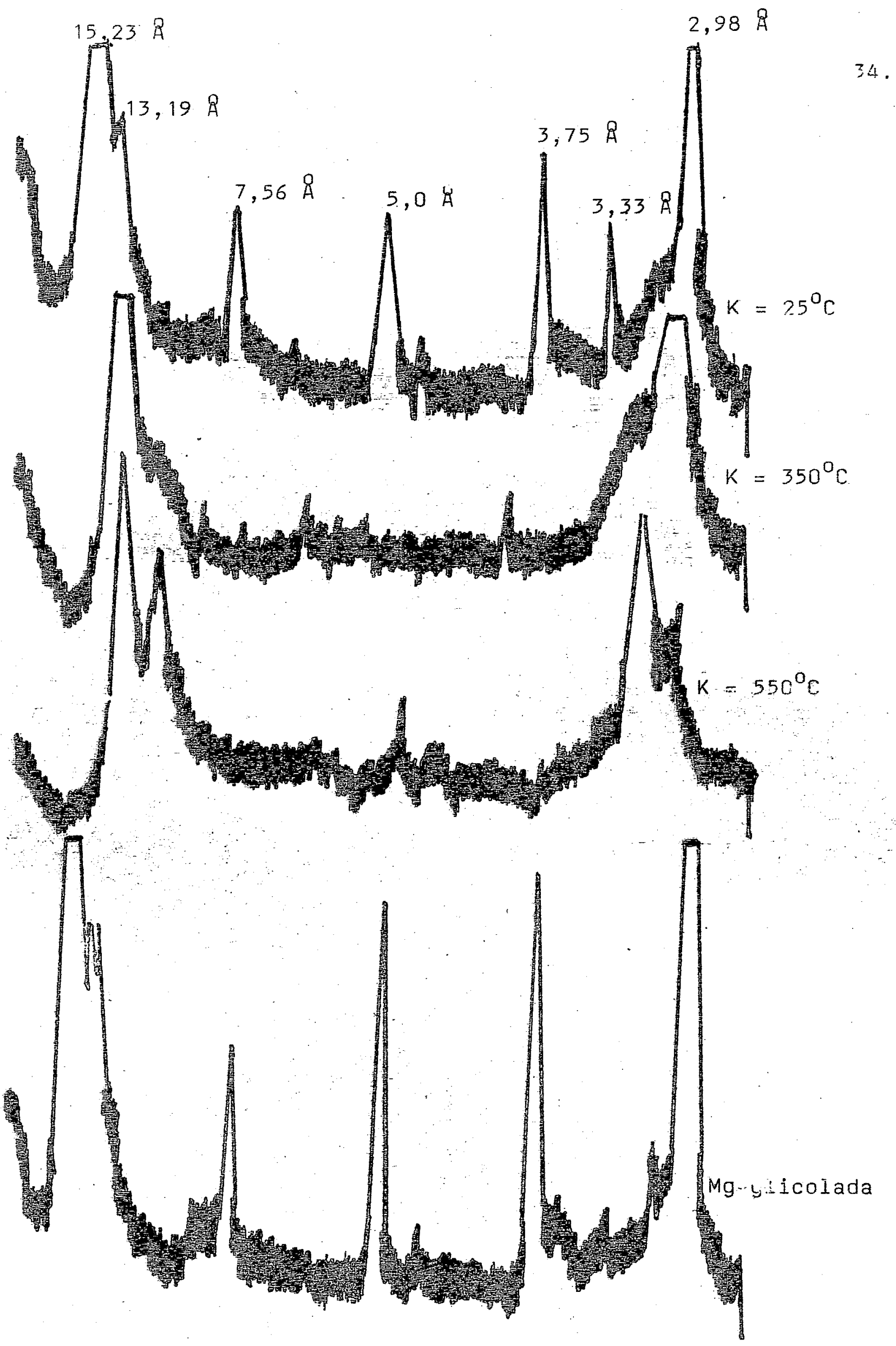

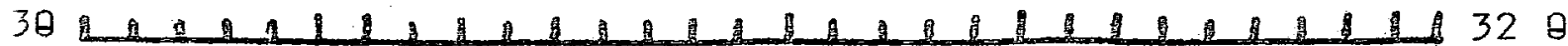

Figura 1 - Difratograma de raio-X da fração argila, da amostra 09 (minério vermiculítico de Piaui). 


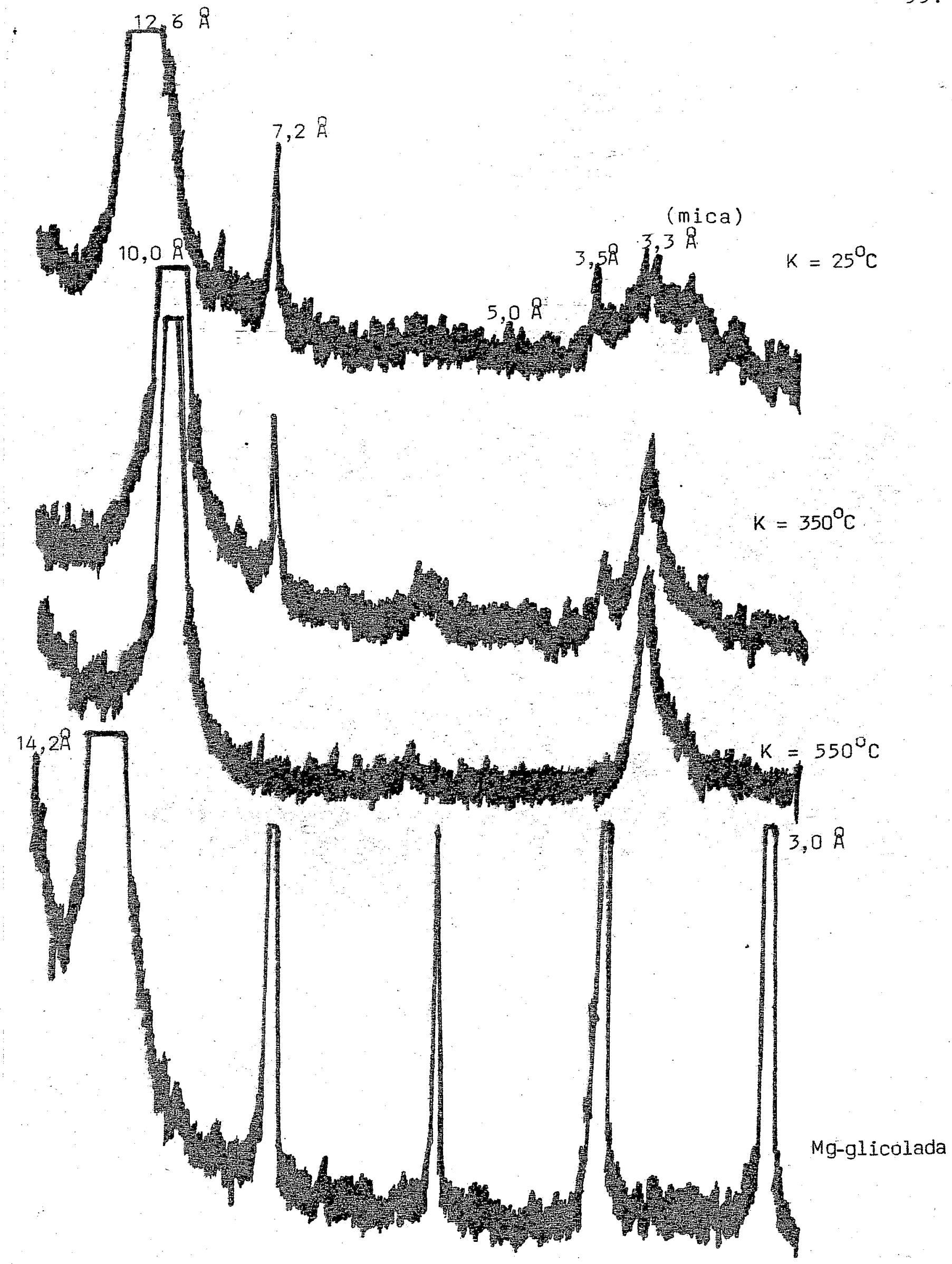

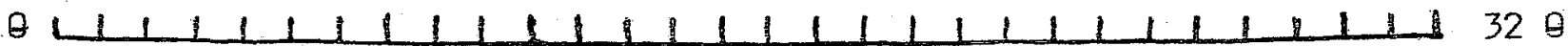

-igura 2 - Difratograma de raio-X da fração argila da amostra 17 (minério vermiculítico de Catalão). 


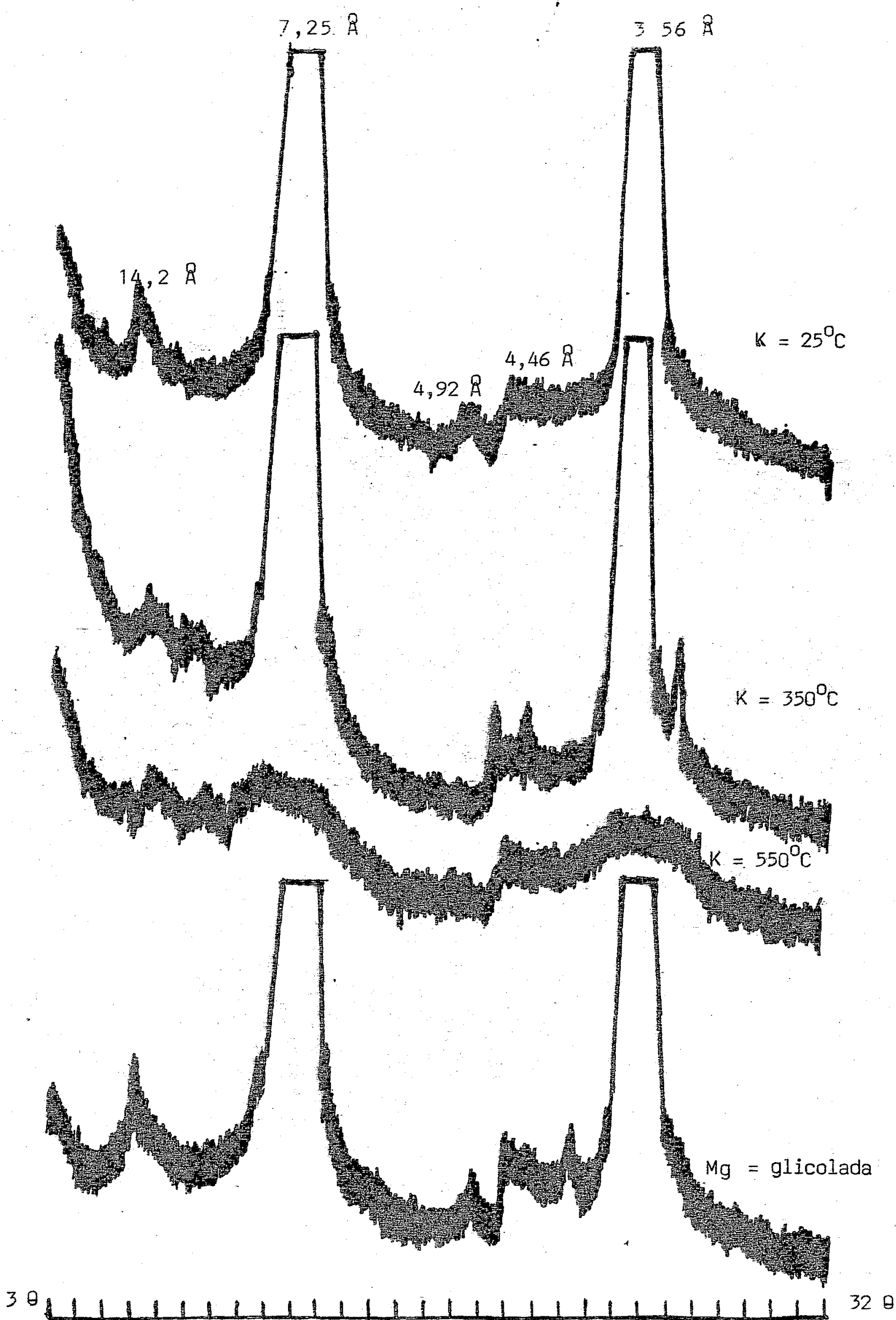

Figura 3 - Difracogramas de raio-X da fração argila da amostra 01 (Solo Latossolo vermelho Escuro-fase arenosa). 


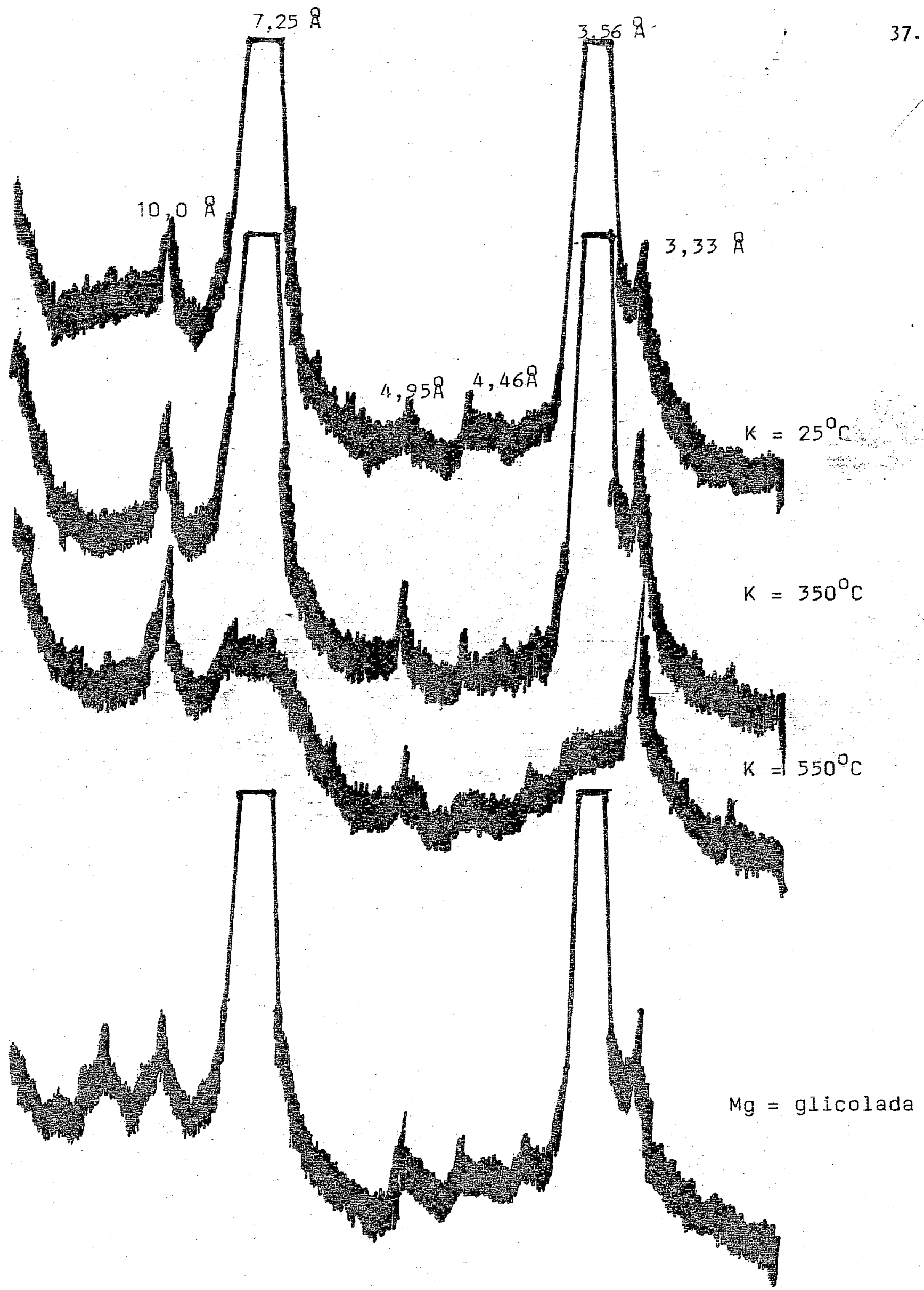

$30 L 1111111111 / 111 / 11111111111111320$

Figura 4 - Difratogramas de raio-x da fração argila da amostra 18 (Solo Podzolizado Lins.Marilia-variação Líns). 
Os resultados obtidos da mineralogia da fração argila das amostras, baseados na identificação dos respecti:vos difratogramas são dados na Tabela 6.

Tabela 6 - Análise mineralógica da fração argila das amostras.

\begin{tabular}{|c|c|c|c|c|c|c|}
\hline \multirow{2}{*}{$\begin{array}{c}\text { Número } \\
\text { da } \\
\text { amostra }\end{array}$} & \multirow{2}{*}{ Amostra } & \multicolumn{5}{|c|}{ Minerais de argila contidos $(x)$} \\
\hline & & $\begin{array}{l}\text { Cauli- } \\
\text { nita }\end{array}$ & $\begin{array}{l}\text { Vermi- } \\
\text { culita }\end{array}$ & $\begin{array}{l}\mathrm{Il} i \\
\mathrm{ta}\end{array}$ & $\begin{array}{l}\text { Clorita } \\
\text { Vermicul. }\end{array}$ & $\begin{array}{l}\text { Musco- } \\
\text { vita }\end{array}$ \\
\hline \multirow[t]{3}{*}{01} & Latossolo Vermelho & & & & & \\
\hline & Escuro-fase arenosa & & & & & \\
\hline & (LVE-fase arenosa) & $x$ & & & $x$ & \\
\hline \multirow[t]{3}{*}{09} & Min. vermiculitico & & 1 & & & \\
\hline & de Paulistania - & & & & & \\
\hline & Piauj (A) & & $x$ & & $x$ & $x$ \\
\hline 17 & Min. vermiculitico & & : & & & . \\
\hline & de Catalão-Goiás & $x$ & $x$ & $x$ & & \\
\hline & (B) & & $\cdot$ & & & \\
\hline \multirow[t]{2}{*}{18} & Solo Podzolizado & & & & & . \\
\hline & $\begin{array}{l}\text { de Lins e Marilia- } \\
\text { var. Lins (SPLM) }\end{array}$ & $x$ & & $x$ & & \\
\hline
\end{tabular}

3.4. Determinação da capacidade de fixação de potássio pelas amostras

Foram transferidas $5 \mathrm{~g}$ de cada amostra de terra para frascos plásticos de $100 \mathrm{ml}$ de capacidade e adicionou- 
se $2 \mathrm{ml}$ de uma solução contendo 125 e 250 ppm de potássio na forma de cloreto de potássio, resultando nas concentrações fi nais de 50 e $100 \mathrm{ppm}$ de $k$ no solo. As soluções foram distribuidas de modo uniforme às terras, procurando uriedecê-las por igual. Para cada tratamento foram feitas quatro repetições e uma testemunha, a qual foi somente umedecida com água destila da.

Os frascos foram tapados, para evitar evaporação e as amostras incubadas por períodos de 10 e 20 dias. Após o período de incubação foram adicionadas às amostras $100 \mathrm{ml}$ de $\mathrm{H}_{2} \mathrm{SO}_{4} \mathrm{O}, 05 \mathrm{~N}$ (solução extratora) e agitadas 20 minutos em agitador horizontal circular, conforme o método de CATANI e JACINTHO, 1974, e lidas no fotometro de chamá.

- Cálculo do potássio fixado

A fixação de potássio foi calculada através da seguinte fórmula de acordo com BARBER (1979).

$$
K \text { fixado }=A-(B-C)
$$

$A=K$ en ppm aplicado ao solo

$B=K$ em ppm obtido após incubação (tratamento)

$C=K$ em ppm originário do solo (testemunha). 
40.

\section{RESULTADOS E DISCUSSÃO}

4.1. Efeito na fixação de potássio causado por doses cres centes de minério vermiculitico de piaui (A) nas amostras dos solos Latossolo Vermelho Escuroffase arenosa e Podzolizado de Lins e Marilia-varjação Lins

As médias das quantidades de potássio fixada pe las amostras com ceores variáveis de minério vermiculitico de Piaui, expressas em pprn e suas respectivas porcentagens, estão contidas nas Tabelas 7 e 8 .

Os resultados apresentados nas Tabelas 7 e 8 , mos tram um acréscimo na capacidade de fixação de potássio pelas amostras dos dois solos, quando o ceor do minério aumentou. ob serva-se que a quantidade de potássio fixado cresceu em valo res absolutos (ppm) e em valores relativos (\% fixada). 


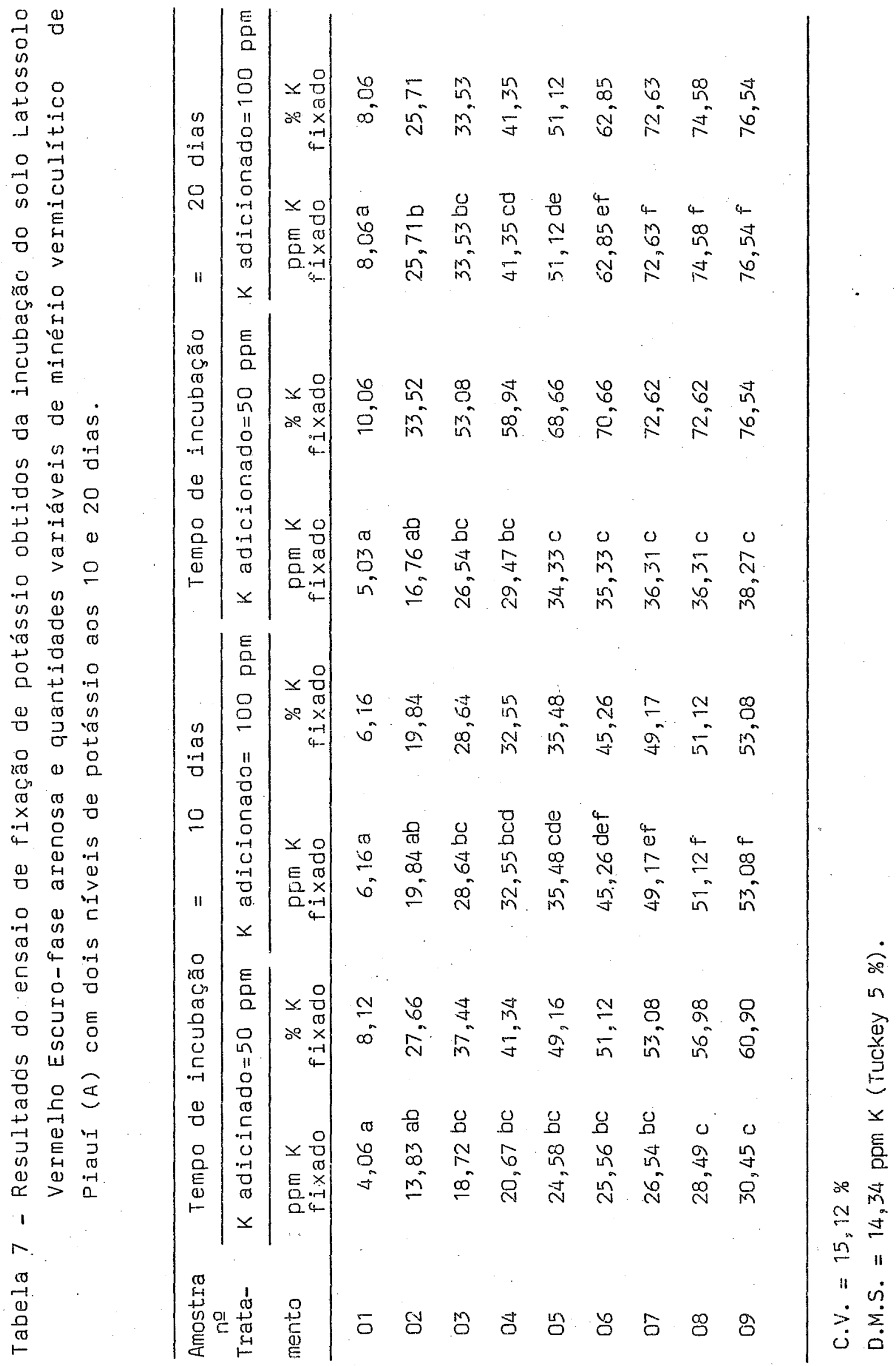




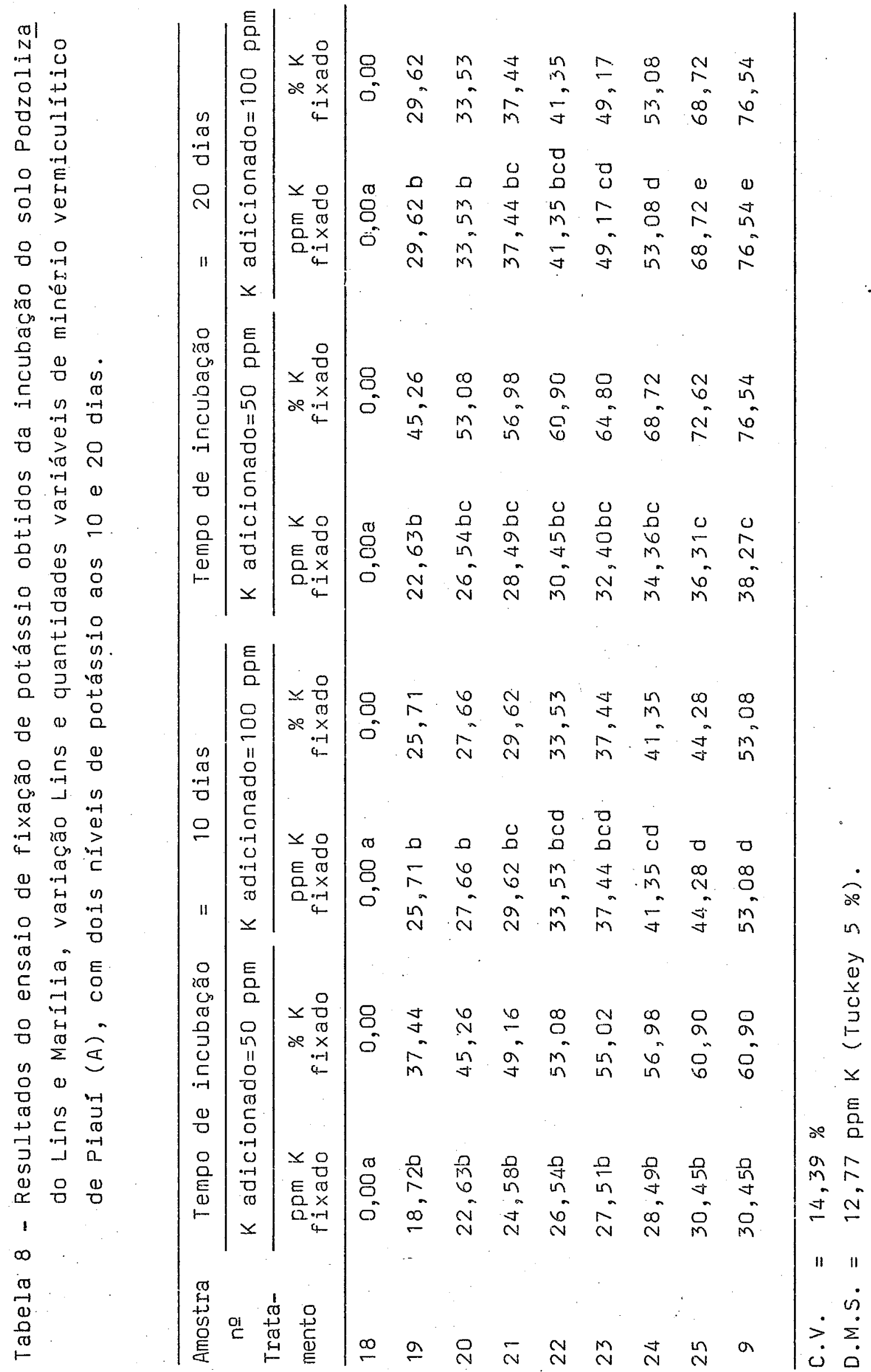


A análise de variância dos tratamentos apre sentada na Tabela 9 , revelou um efeito significativo da argila adicionada, do tempo de contato e da dose de potássio adicionada sobre a porcentagem de potássio fixada. Para o estudo das interações, efetuou-se o desdobramento das mesmas. Po de-se observar que as interações duplas foram significativas.

Dos dados das Tabelas 7 e 8 , pode-se observar que a argila vermiculitica de Piaui ( $A$ ) teve um grande efeito nivelador nas quantidades de potássio fixada, quando as amostras apresentaram maiores teores do minério, aproximando-se das porcentagens fixadas pelo minério puro. Pode-se observar que o solo Podzolizado sem a adição do minério não fixou potássio, mas com a adição de minério houve uma maior fixação quando comparado com o solo Latossolo.

As ilustrações gráficas dos tratamentos com os solos Podzolizados e Latossolo são mostradas pelas Figuras 5 e 6, onde as porcentagens de potássio fixado em função do teor de minério vermiculitico de Piauí adicionado estão representa- 


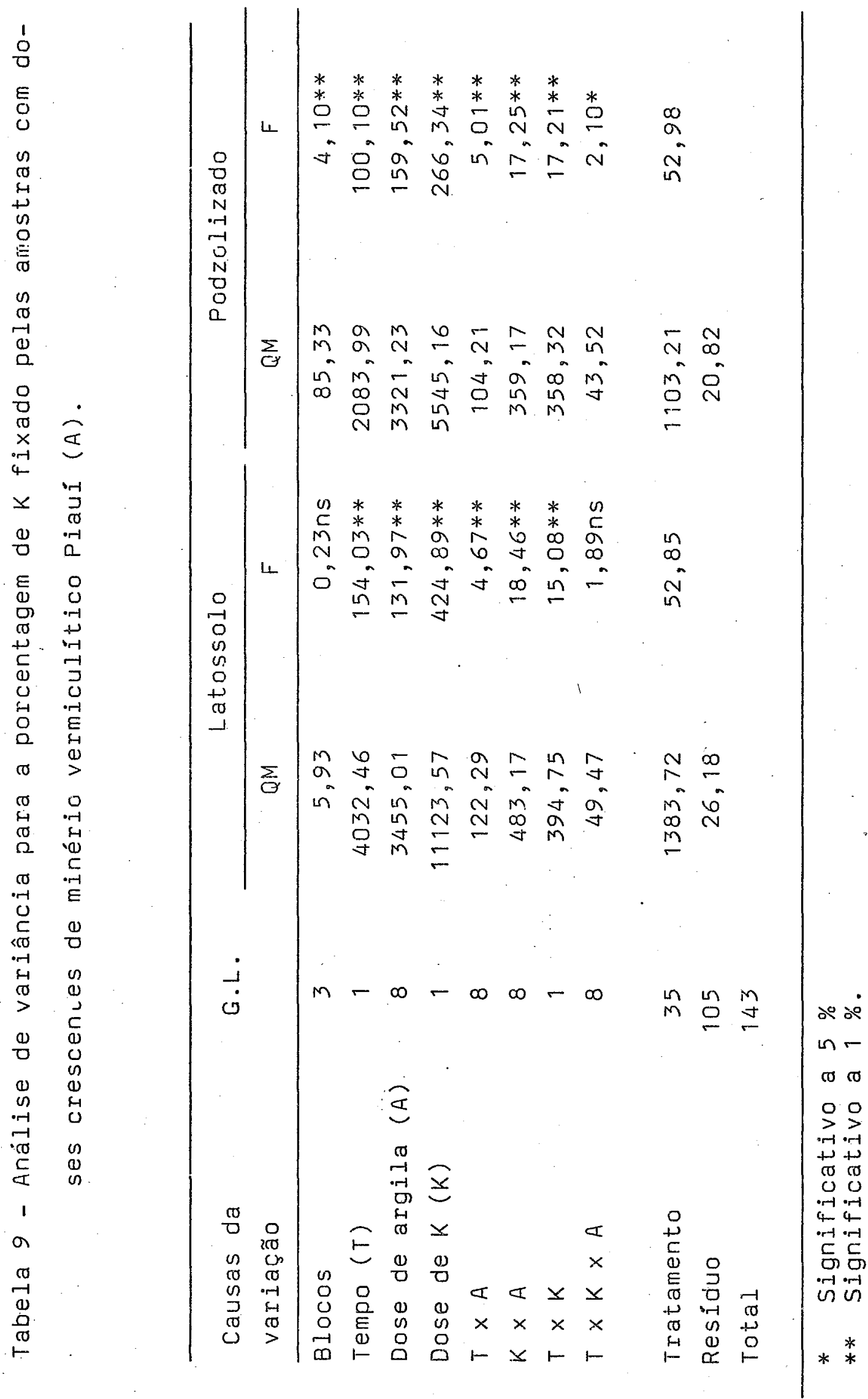




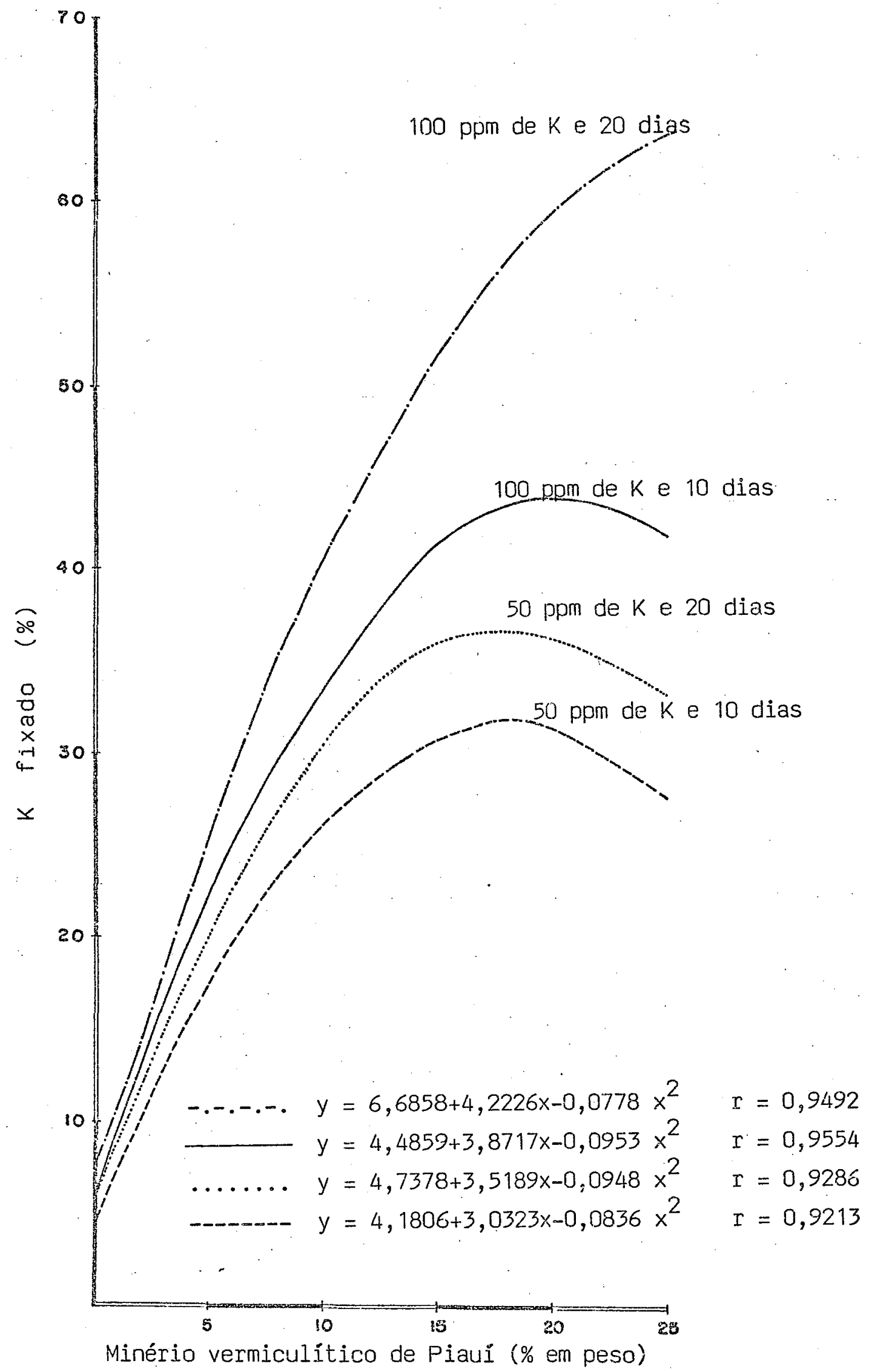

Figura 5 - Curvas de fixação de $K$ para o solo Podzolizado com doses crescen tes de minério vermjculitico de Piauí 
45.

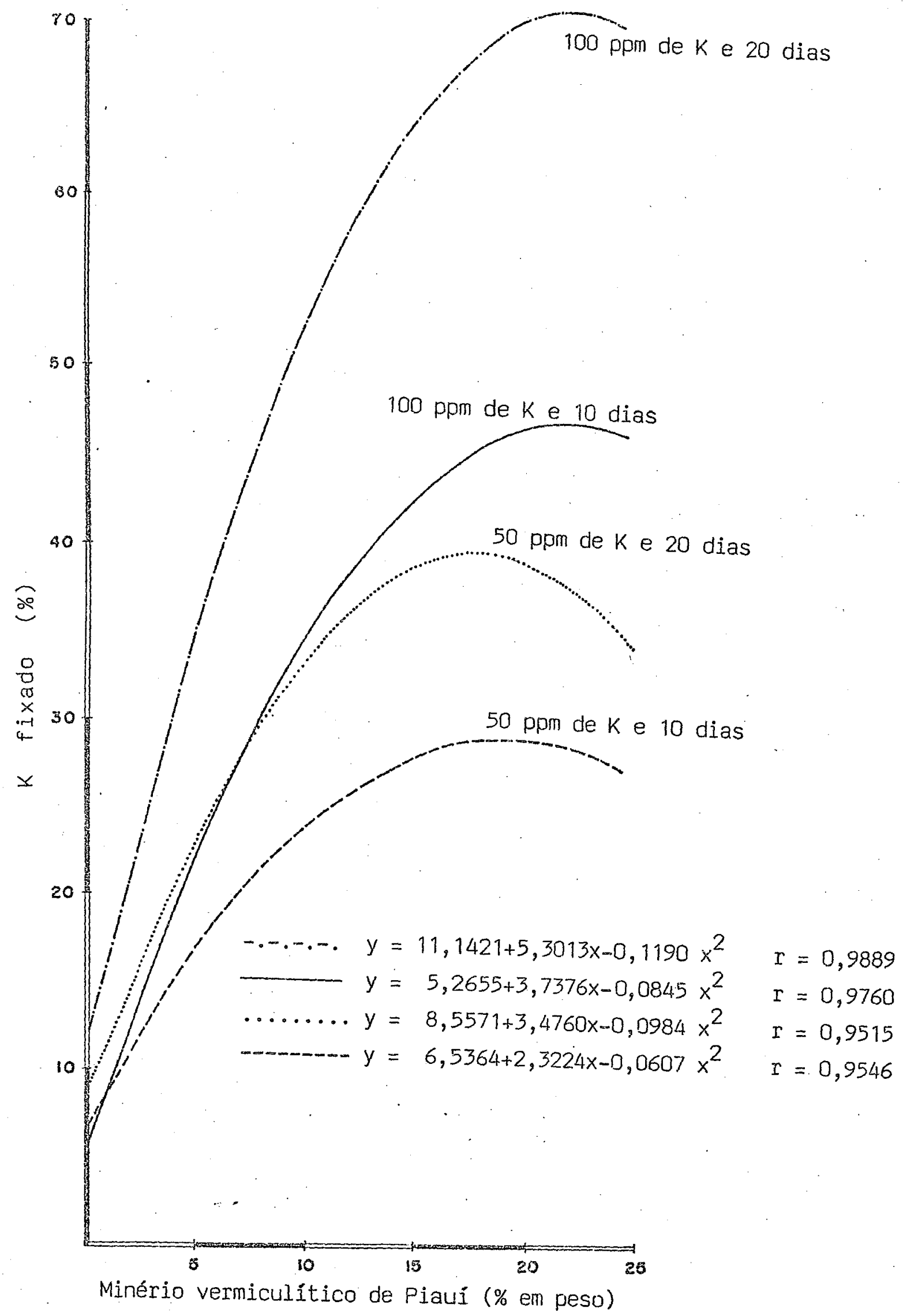

Figura 6 - Curvas de fixação de $K$ para o solo Latossolo com doses crescentes de minério verniculítico de piauí. 
dos, sendo as equações de regressão de segundo grau com altos valores para $r$.

As curvas apresentadas (Figuras 5 e 6), mostram um comportamento seinelhante no mesmo solo quando submentidos aos diferentes tratamentios. Verifica-se que a variação na fixação com as doses maiores de vermiculita de Piaui,foi pequena e nas doses menores a variação na fixação de potássio foi maior.

Nota-se que a fixação aumencou em valores absolutos (ppm) com o aumento na quantidade de potássio e, com o aumento no tempo de incubação.

4.2. Efeito na fixação de potássio causado por doses cres centes de minério vermiculitico de Catalão (B), nas amostras dos solos Latossolo Vermelho Escuro-fase arenosa e Podzolizado de Lins e Marilia -variação Lins

As médias das quantidades de potássio fixada com teores variáveis de minério vermiculjtico de Catalão, expressas em ppm e suas respectivas porcentagens, acham-se nas Tabelas 10 e 11 .

Os resultados apresentados mostram que a fixação de potássio pelas amostras dos solos, quando o teor de minério aumentou, não variou. Observa-se que a quantidade de potássio 


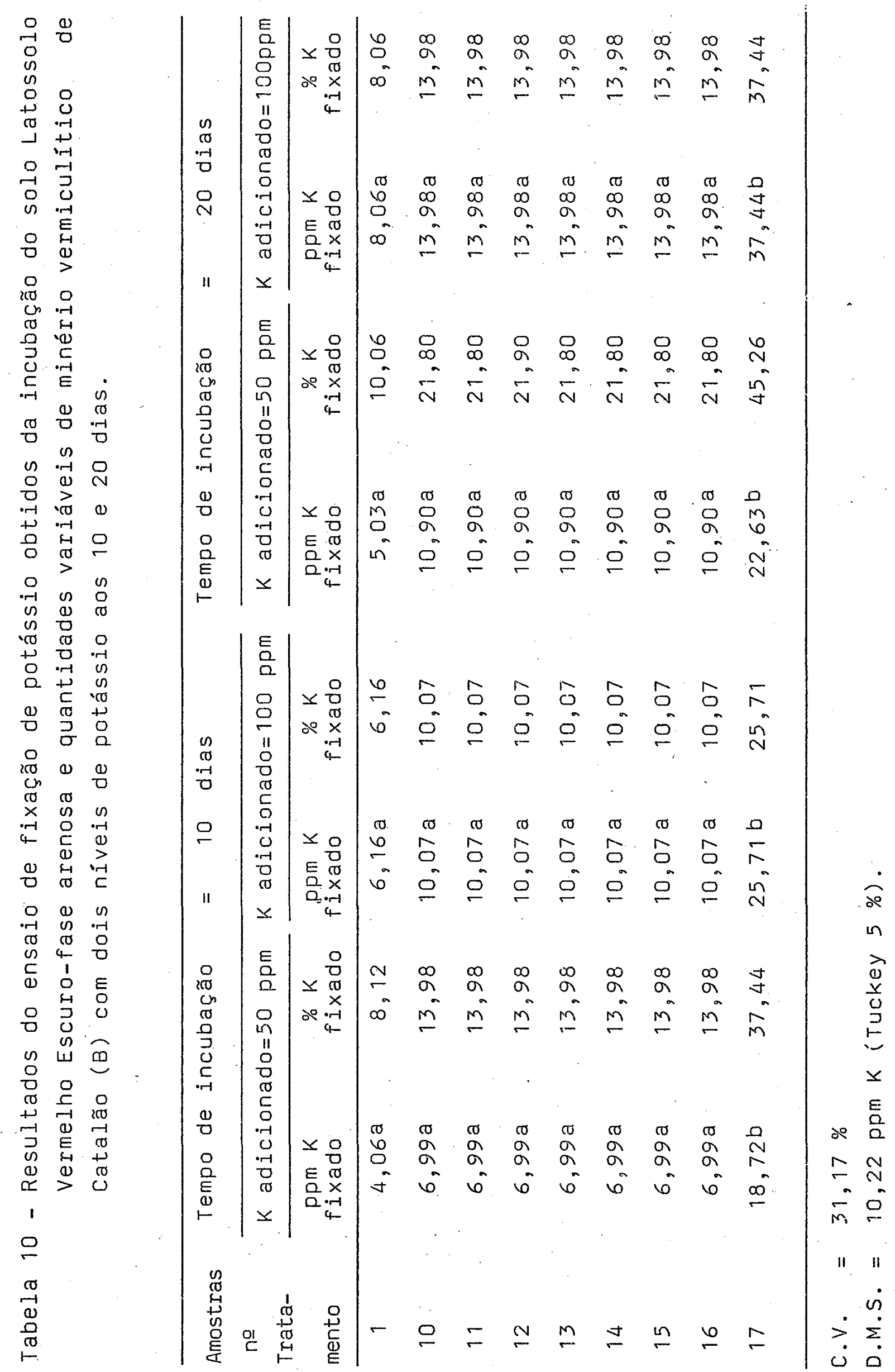




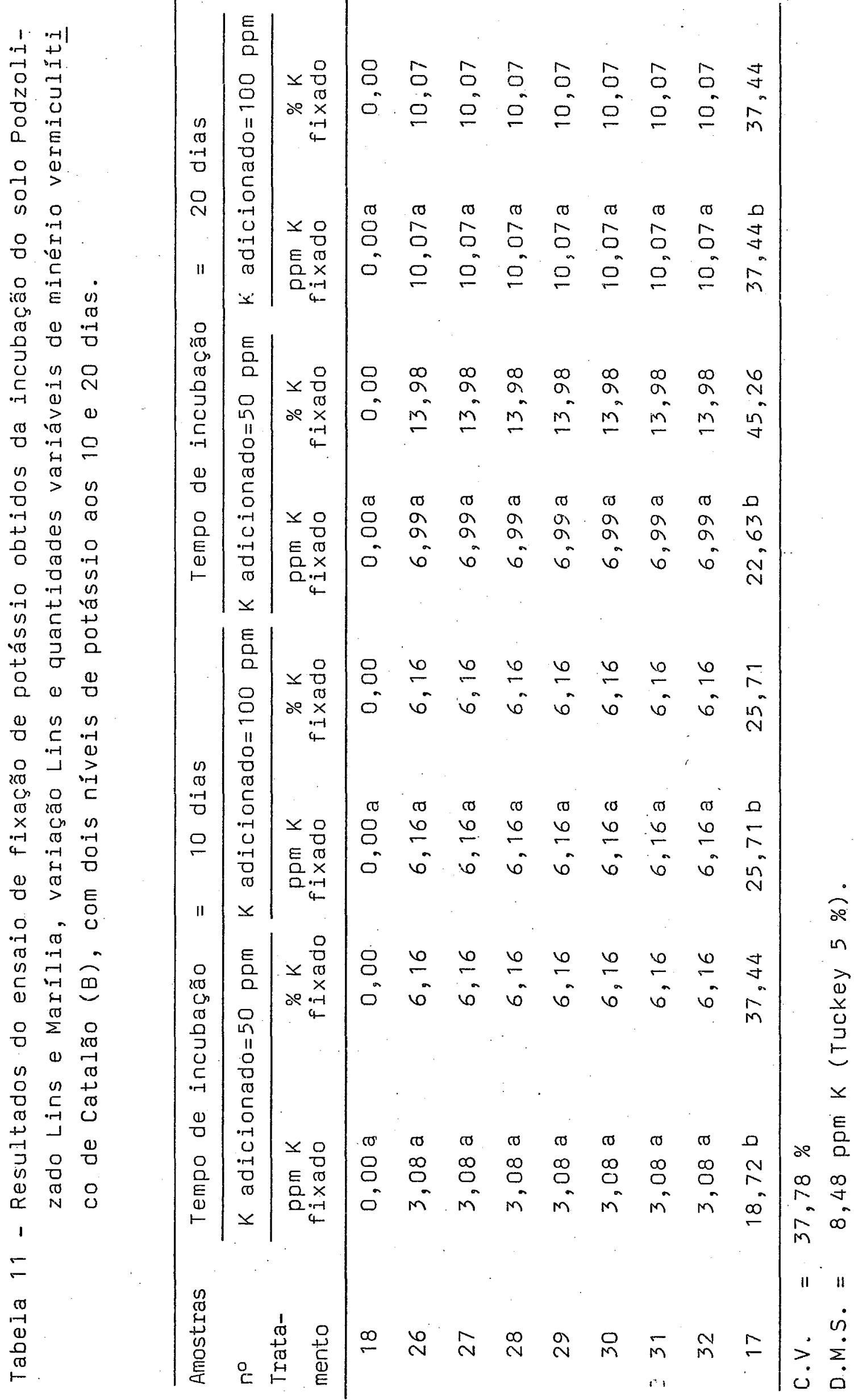

49. 
fixada permaneceu constante, tanto em valores absolutos (ppm), quanto em valores relativos (\% fixada).

A análise de variâncja apresentada na Tabela 12 revelou um efeito significativo da argila adicionada, de tempo de contato e da dose de potássio adicionada. Para o estudo das interações, efetuou-se o desdobramento das mesmas. Pode se observar que apenas a interação da dose de potássio e argila adicionada foi significativa.

Confrontando os teores de potássio fixado pelos solos com os fixados peló minério puro, verifica-se que os solos fixaram uma quantia bem menor, e que o solo Latossolo vermelho Escuro-fase arenosa, possui uma capacidade de fixação malor do que o solo Podzolizado de Lins e Marilia, variação Lins.

As ilustrações gráficas dos tratamentos com os solos Podzolizado e Latossolo são mostradas pelas figuras 7 e 8, onde as porcentagens de potássio fixado em função do teor de minério vermiculitico de Catalão aplicado estão representadas, sendo a equação de regressão de segundo grau com valores altos para $r$ :

As curvas das Figuras 7 e 8 mostram que a fixação de potássio foi maior no solo Latossolo e que aumentou de 
음

E

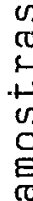

$n$
0
0
0

$x$

$x$

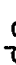

E.

a 0

त)

$+4$

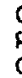

$\pi$

0

co

<

倞

$\stackrel{\circ}{0}$

.

.$$
\text { 밍 }
$$$$
\text { ! }
$$$$
\text { N }
$$$$
\frac{\pi}{\pi}
$$

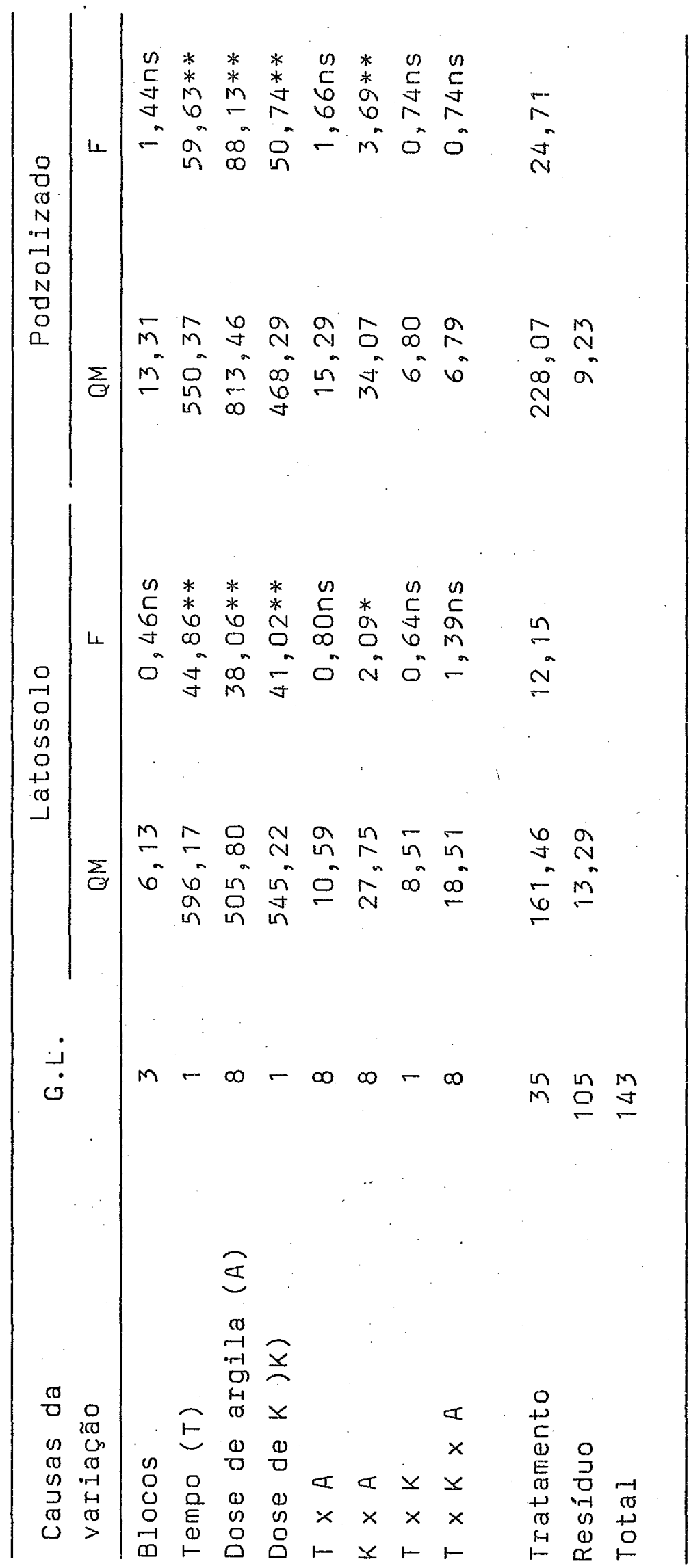




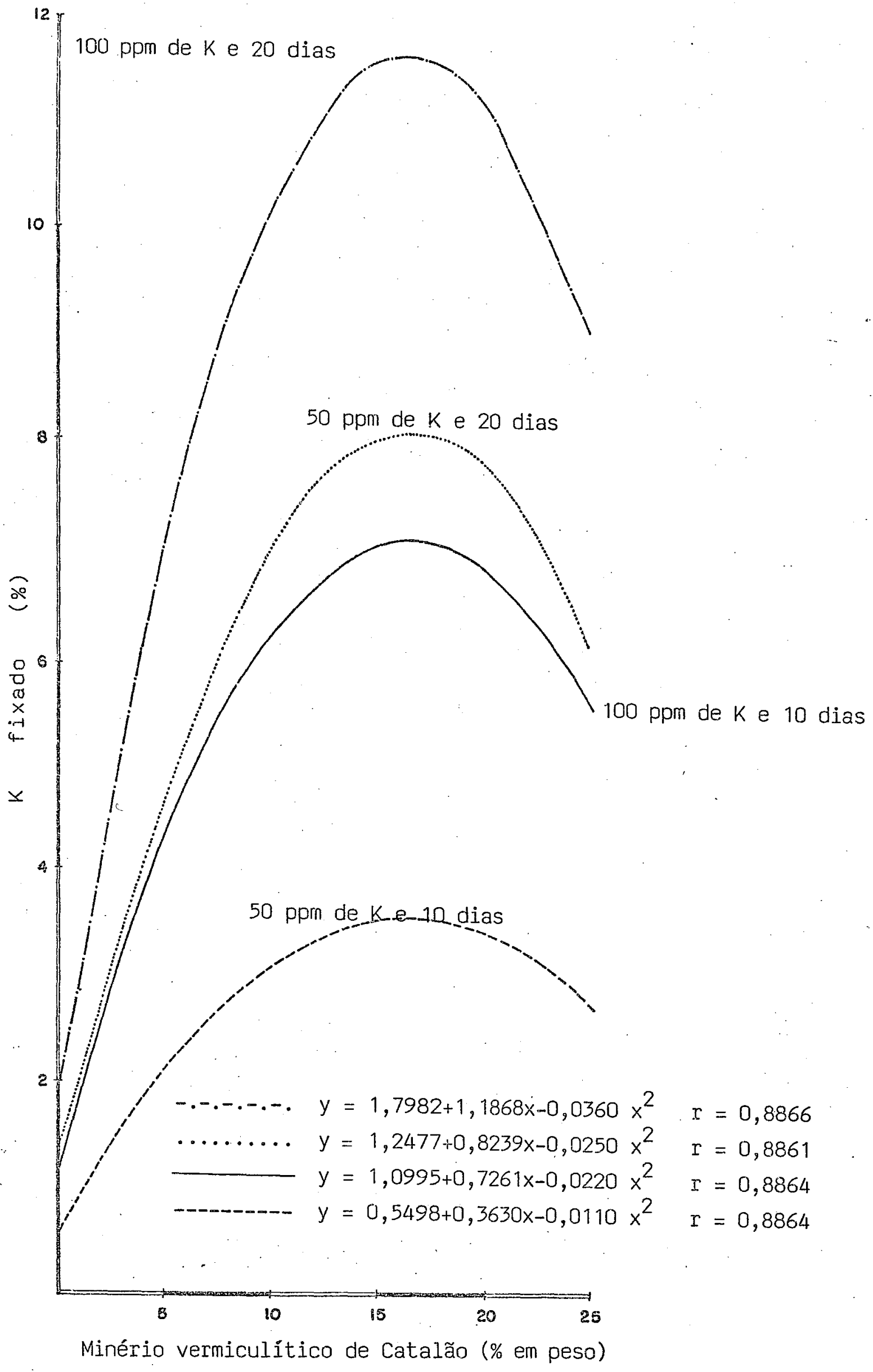

52. 


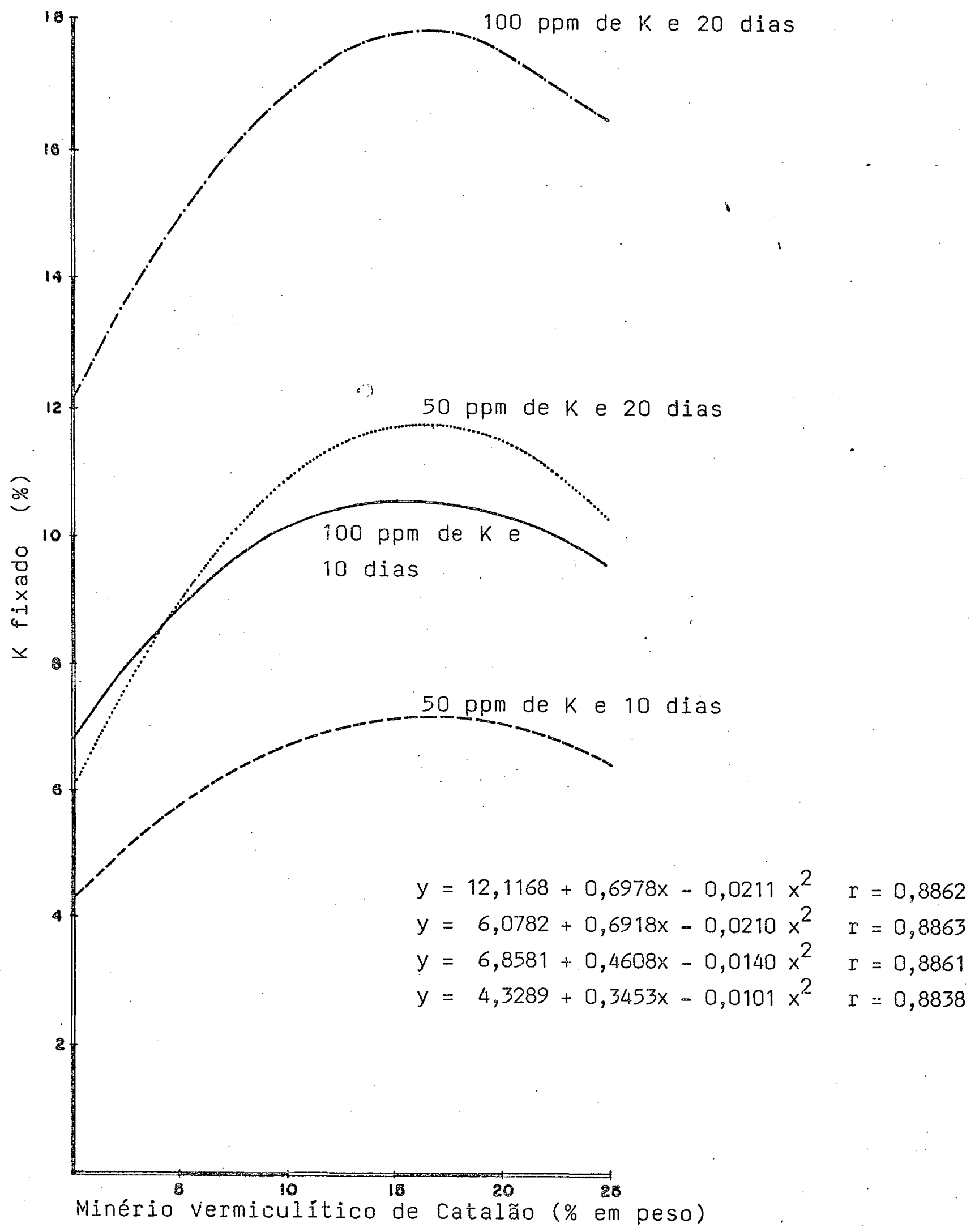

Figura 8 - Curvas de fixação de K para o solo Latossolo com doses crescentes de minério vermiculítico de Catalão. 
54.

acordo com o aumento na dose de potássio e com o tempo de incu bação.

Admite-se que a îxação do potảssio está relacio nada com várias caracteristicas do solo. Pretende-se neste tra balho discutir a fixação, tomando como base o teor e a natureza da argila e, correlacionando-os com os fatores pH e cálcio, capacidade de troca de cation, condições de umidade e secagem dos solos.

Observando as tabelas 3 e 4, que apresentam as características físicas e quimicas das amostras, nota-se um efeito de diluição: ou de concentração nas caracteristicas do so lo original, provocadas pelo aumento do teor de argila adiciona:da. O aumento de $\mathrm{pH}$ nas amostras com doses crescentes de vermi culita é consequência do minério, que apresenta um pH alcalino, associado a elevados teores de $\mathrm{Mg}$, que acarreta um aumento na CTC e na porcentagem de satuação em bases nas amostras.

\subsection{Influência do teor e da natureza de argila na fixação}

Numerosos trabalhos têm mostrado una influência positiva do teor e da natureza da argila na fixação. A mineralogia de argila tem sido relatada como um importante fator para a fixação de potássio nos solos. DENNIS e ROSCOE (1962), relata 
ram que a fixação tem correlação positiva com a presença de veI miculita.

A fixação do potássio tem sido relacionada com a presença de minerais do tipo 2:1 (JOFFE e LEVINE, 1947; PAGE e BAVER, 1941; STANFORD, 1948).

Nas Figuras $1,2,3$ e 4 e na Tabela 6 , verifica se a composição mineralógica dos minéries vermiculíticos e dos solos, notando a presença de caulinita em ambos os solos e no Latossolo a ocorrência de clorita-vermiculita e no podzolizado a ilita. Nos minérios vermiculiticos observou-se uma variação na mineralogia, sendo que no minério vermiculitico de piaui, constatou-se a presença de diversas argilas principalmente : a vermiculita, muscovita e clorita-vermiculita e no minério vermi culitico de Catalão observou-se a presença da caulinita, vermiculita e ilita.

ARIFIN et alii (1973), em experimentos realiza dos em solos dos Estados Unidos, concluiram que a diferença na fixação do potássio foi devido provavelmente à presença ou ausência de micas especificas nas argilas. As micas intemperizadas podem ter algumas zonas em cunha, consideradas altamente se letivas para o potássio e a presença dessas zonas altamente seletivas diminuem de acordo com a sequência de intemperização: mica $\rightarrow$ ilita $\rightarrow$ vermiculita $\rightarrow$ montmorilonita. 
DOWDY e HUTCHESON, relataram a importância da ilita na fixação de potássio. STANFORD (1947), relatou que a montmorilonita fixou menos potássio quando úmida e a iljta fixou uma quantia maior. Segundo MOSS e COULTER, a caulinita fi $x$ a menos potássio do que a montmorilonita.

Neste trabalho, verificou-se uma variação na fi xação nos dois minérios vermiculiticos, sendo que no minério de Piaui a fixação foi main do que no de Catalão, e isto prova velmente deve ser devido a variação na composjção mineralógica.

Diversos mecanismos tem sido propostos para explicar a fixação do potássio. PAGE a BAVER(1941), propuseram uma teoria, que explica a fixação em vazios nos minerais de argila 2:1. WEAR e WHITE (1951), concluiram que quando o comple xo de troca é saturado com ions potássio, estes são presos por forças atrativas nos octaedros e tetraedros.

RICH e BLACK (1964), relataram a presença de mui tas zonas em forma de cunha nas argilas $2: 1$, as quais são consideradas altamente seletivas para o potássio. O efeito dessas zonas na fixação ou na seletividade para o potássio, foi deter minada pelos seus números e posição no cristal de argila. Se. a zona estiver localizada na extremidade da particula a porcen tagem de potássio fixada será pequena, mas se ocorrer dentroda particula,isto poderá resultar maior quantidade de potássio fi xado. 
REEUWIJK e VILLIERS (1968), postularam um mecanismo de "peneira", para explicar a fixação, segundo o qual os ions de potássio hidratados, tornam-se fixados pela oclusão nesses poros.

\subsection{Influência do pH}

Para a reação do solo, existe uma correlação pD sitiva e significativa pntre o pH e as porcentagens de potássio fixado. Na tabela 4, notá-se aumento no pH com o aumento no teor de argila, em consequência do minério, que apresenta um pH alcalino.

STANFORD (1948), sugeriu existir uma relação en tre o pH e a fixação. Ele conduziu experimentos, onde o pH va riou de 3,8 a 9,8 com adição de $\mathrm{NaOH}$. Os dados obtidos mostra ram que as variações no pH foram acompanhadas por efeitos expressivos na fixação, sendo que em $\mathrm{pH} 9,0$ foi verificado uma máxima fixação. Estes resultados sugerem que ions $\mathrm{H}^{+}$que ocupam posições dentro do cristal de argila, com a elevação do pH são neutralizados $e$ isto facilita a entrada do ion $K$ dentro de posições no cristal de argila.

Diversos outros autores como Van REEWWIJK e VILLIERS (1968): ; Duchaufour (1970), citado por RAFAHI (1980), abser varam que uma elevação no pH e a abundância de calcário, nos 
solos favoreceram a fixação. HARRIS (1937), relatou o efeito positivo do óxido de cálcio hidratado na fixação do potássio, devido a elevação do $\mathrm{pH}$. Isto mostrou que com o aumento do $\mathrm{pH}$ ocorreu a liberação de zonas antes ocupadas pelo Al, Fe e.H, que favoreceram então a fixação do potássio.

4.5. Efeito do tempo de contato entre o ion potássio e o sólo na fixação

Os dados apresentados nas Tabelas 7,8,10 e 11 , mostram que a fixação de potássio cresce com o aumento no tempo de contato entre as amostras de solo e o ion potássio adi cionado, tanto em valores absolutos, quanto em valores relativos (porcentagem de potássio fixado).

A análise estatistica revelou, para todos os tra tamentos, um teste $F$ significativo, indicando a influência positiva do periodo de incubação no processo de fixação.

As Figuras $5,6,7$ e 8 , representando as porcen tagens de potássio fixado pelos solos com teores variáveis de minérios, nas duas doses de potássio e nos dois tempos de incu bação, ilustram as curvas dos tratamentos incubados em tempos diferentes, indicando variação, na porcentagem de potássio fi.. xado, no periodo de 10 e 20 dias, mas sempre mostrando que a curva de maior fixação corresponde aos tratamenios com 20 dias de incubação. 
Verifica-se que ao estabelecer um indice 100 para as quantidades de potássio fixado aos 20 dias de incubação, que aos 10 dias já havia sido fixado para o minério vermiculití co de Piaui, aproximadamente $70 \%$ da quantidade firal e para o minério vermiculítico de Catalão variou de 40 a $70 \%$ da quantidade final. Estes valores relativos, para todos os tratamentos são apresentados na Tabela 13.

Os resultados obtidos concordam com outros traba Ihos, os quais estudam os fatores, que afetam a fixação, onde se demonstram que a maior parte do potássio adicionado foi fixa do em pouco tempo.

AMBERGER et alii (1974), através de experimentos realizados em vasos, por um período de três anos, concluiram que a maior parte do potássio foi fixado dentro de poucas semanas, após a aplicação.

\subsection{Efeito da quantidade de potássio adicionado na fixação}

Os resultados deste trabalho, contidos nas Tabelas $7,8,10$ e 11 , mostram que com o acréscimo das doses de potássio adicionadas ao solo, a fixação aumentou em valores absolutos (ppm de $\mathrm{k}$ fixado), mas diminuiu em valores relativos (\% de $K$ fixado) e no solo Podzolizado de Lins e Marília, variação Lins, com o minério vermiculitico de Catalão (B), a fixação au- 


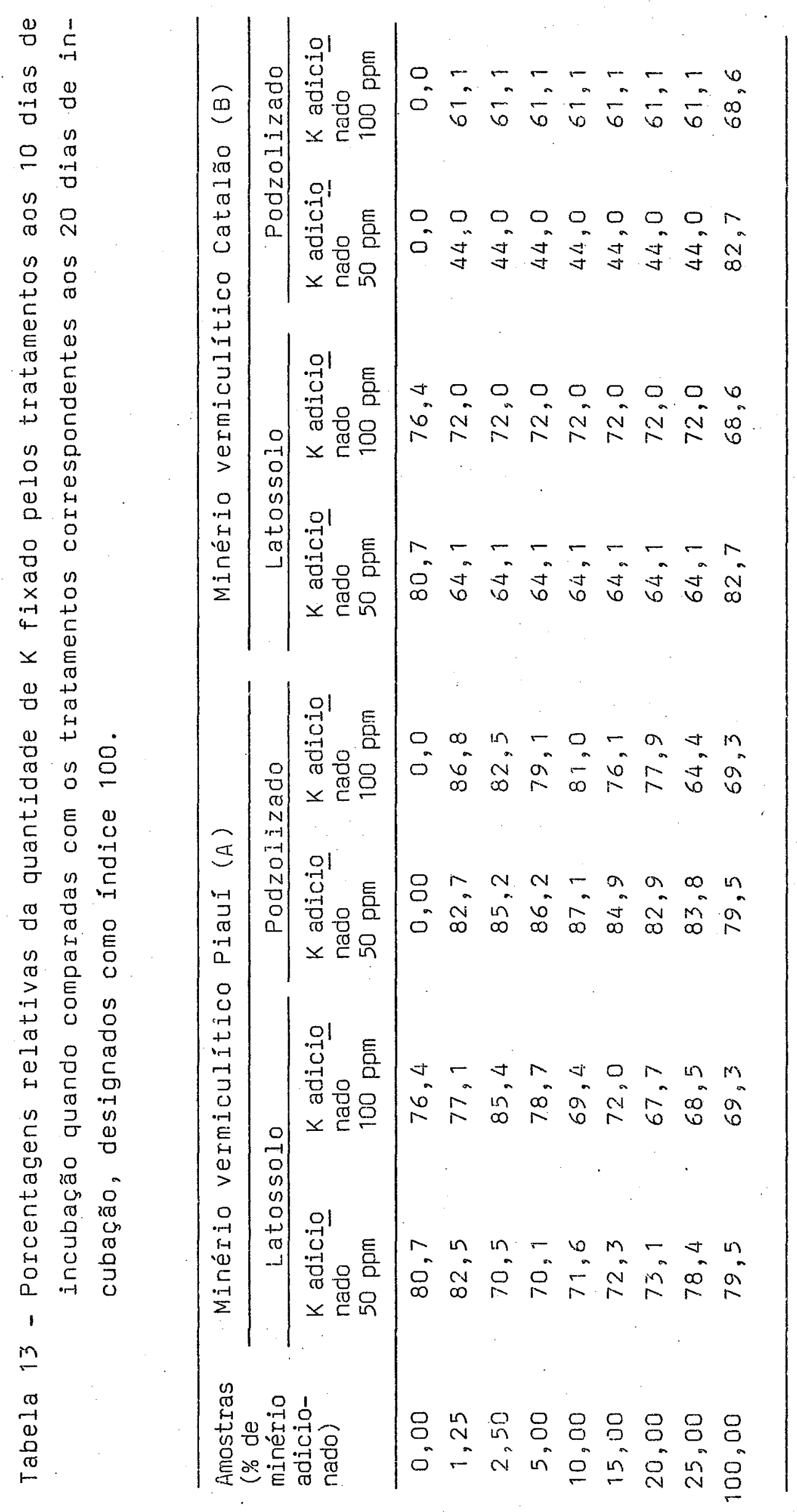

60. 
mencou em valores absolutos, mas pemaneceu igual em valores re lativos.

Ao estudar-se o efeito das doses de $K$ aplicado, a análise estatistica revelou um efeito altamente significativo, indicando sua influência no fenômeno de fixação.

Em experimentos realizados AHMAD e DAVIS (1970), em Trinidad, observaram uma influência altamente significativa da concentração de potássio adicionado na fixação. Nas Tabelas $7,8,10$ e 11, observa-se que a fixação aumentou com o teor de potássio adicionado, mas em termos percentuais houve um decréscimo na fixação. Isto concorda com os dados de AHMAD e DA VIS (1970), os quais em seus experimentos observaram que apesar da fixação aumentar com a concentração, em percentual, a fixaçăo teve tendência para decrescer com o aumento na conceritração de potássio adicionado. Dados similares foram obtidos por VOLK (1934), onde a fixação aumentou, rapidamente, com o aumento na concentração de potássio.

Para explicar a influência da quantidade de potássio adicionado, no fenômeno da fixação, tem-se relacionado com a tendência que o potássio possui para manter o equilíbrio no solo. Uma adubação de potássio solúvel causa um aumento no potássio trocável e não trocável, que seria fixado em zonas na estrutura dos minerais $2: 1$. 
62.

4.7. Influência da umidade e secagem na fixação

Muitos experimentos têm comprovado o efeito da umidade e secagem na fixação de potássio.

RANEY e HOOVER (1946), obseivaram a fixação em solos de Susquehamna, Mississipi, e observaram que a fixação au meritou com o secamento dos solos.

DEMUMBRUM e HOOVER (1958), relataram que a vermí culita seca, em estufa, fixou quase $100 \%$ para $10 \mathrm{me} \mathrm{K} / 100 \mathrm{~g}$ de argila.

Em experimentos reajizados en solos de Miami e Hagerstown, VOLK (1934), conclui que praticamente não ocorreu fixação de potássio sob condições de secamento, mas que na condição de umedecimento e secagem a fixação aumentou.

Neste trabalho, as amostras foram incubadas em frascos e os mesmos foram tapados para evitar a perda de umidade, não havendo então um processo de secamento das amostras mas, segundo diversos autores, o secamento causa um aumento no teor de potássio fixado; provavelmente se tivessemos trabalhado com condição de umedecimento e secamento a porcentagem de potássio fixado teria sido maior. 
63.

\section{CONCLUSÕES}

De acordo com os resultados apresentados no pre sente trabalho, foram obtidas as seguintes conclusões:

1. O minério vermiculitico de piaui (A) fixou uma maior quantidade de potássio do que o minério vermiculitico de Catalão (B). O solo Podzolizado de Lins e Marilia-varia ção Lins, quando em mistura com o minério de Piaui, fixou mais potássio do que o solo Latossolo Vermelho Escuro-fase arenosa.

2. Para o minério vermiculitico de Catalão

- solo Latossolo Vermelho Escuro-fase arenosa fixou mais potás sio do que o Podzolizado de Lins e Marillia-variação Lins.

3. A fixação aumentou com o aumento no teor de argila até se aproximar da fixação no minério puro, tanto en valores absolutos ( $p p m$ ) como em valores relativos (porcentagem) para o minério vermiculitico de piaui $(A)$ e, no minério vermiculítico de Catalão (B) não houve variação na fixação. 
4. Aumentando a dose de potássio de $50 \mathrm{ppm}$ para 100 ppm, para um mesmo tempo de incubação a quantidade de potássio fixado cresceu em valores absolutos (ppm), mas diminuiu em valores relativos (porcentagem).

5. Para o minério vermiculitico de Piaui (A) , em torno de $70 \%$ de potássio foi fixado nos 10 dias de incubação, quando comparados com a porcentagem fixada, aos 20 dias, independente do teor adicionado e da porcentagem de argila pre sente no solo e para o minério de catalão (B) em torno de 40 a $70 \%$ foram fixados aos 10 dias.

6. Observou-se que existem variações no comportamento dos minérios vermiculiticos $(2: 1)$ em relação à capacidade de fixação de potássio, dependendo de sua origem, mineralogia e granulometria. 
65.

\section{LITERATURA CITADA}

AHMAD, N. e C.E. DAVIS, 1970. Forms of potassium fertilizers and soil moisture content on potassium status of a Trinidad soil. Soil Science. Baltimore, 109(2): 121-126.

ALBRECHT, W.A., 1943. Potassium in the soil colloid complex and plant nutrition. Soil Science, Baltimore. 55: 13-21.

ARIFIN, H.P.F. e K.H. TAN, 1973. Potassium fixation and re.constitution of micacious structures in soils. Soil science. Baltimore, 116(1): 31-35.

ATTOE, 0.J., 1948. Fixation and recovery by oats of potash applied to soils. Proceedings of Soil science Society of America. Madison, 13: 112-115. 
66.

AYRES, A.S., 1941. Sorption of potassium and ammonium by soils as influenced by concentration and the degree of base saturation. Soil Science. Baltimore, 51: 265-272.

BAJWA, I., 1980. Soil clay mineralogies in relation to fertility management: Effect of soil clay mineral compositions on potassium fixation under conditions of Witland rice cul ture. Plant Analisys. New York, 11(10): 1019-1027.

BAJWA, M.I. 1981. Soil beidellite and its relation to pro blems of potassium fertility and poor response to potassium fertilizers. Plant and Soil. The Hague, 62: 299-303.

BARBER, R.G., 1979. Potassium fixation in some kenyan soil. Journal of Soil Science. Oxford, 30: 785-792.

BARSHAD, I. Cation exchange in micaceous minerals: I. Replaceability of the jnterlayer cations of verniculite with ammonium e potassium ions. Soil Science. Baltimore, 77: 463472. 1954.

BITTENCOURT, V.C. e I. SAKAI, 1975. Lixiviação do potássio nativo de solos tropicais. Boletim Cienuifico do CENA. Piracicaba, 27: $1-21$. 
BRADY, N.C., 1983. Colóides do solo: sua natureza e signifí cação prática. In: __ Natureza e Propriedades do Solo. 6a. ed.. Rio de Janeiro, Livraria Freitas Bastos S/A. p. 73113.

BRAGA, J.M. E J. YAMADA, 1984. Uso eficiente de fertilizantes potássicos. In: ESPINOZA, E. \& OLIVEIRA, A, J. (eds.). Anaís do Simpósio Sobre Fertilizantes ra Agricultura Brasileira. Brasilia, p. 291-321.

BRAY, R.H. e E.E.DE TURK. The release of potassium from non-re placeable forms in Illinois soil. Proceedings of soil science of America. Madison, 3: 101-106.

CARMO, A.J.B., 1986. Fertilizantes e matérias-primas: preços, produção e consumo de 1980 a 1985. Fertilizantes-IPT; São Paulo, $\underline{8}(2): 1-5$.

CARSON, C.D. E J.B. DIXON, 1972. Potassium selectivity in ce $\underline{\underline{r}}$ tain montmotillonitic soil clays. Proceedings of soil science of America. Madison, 36: 838-843.

CATANI, R.A. e A.O. JACINTHO, 1974. Avaliação da fertilidade do solo métodos de análise. Piracicaba, Livroceres, $61 \mathrm{p}$. 
DEMUMBRUM, L.E., 1958. Potassium fjxation as affected by mineralogy in some soils derived from argillaceous chalk. Soil Science. Baltimore, 86: 276-281.

DEMUMBRUM, L.E. e C.D. HOOVER, 1957. Potassium release and fixation as influenced by ilitite and vermiculite, as single minerals and in mixtures. Proceedings of soil science society of America. Madison, 21: 498-501.

DEMUMBRUM, L.E. e C.D. HOOVER, 1958. Potassium release and fixation related to illite and vermiculite as single mine.rals and in mixtures. Proceeding of Soil science society of America. Matison, 22: 222-225.

DENNIS, E.J. e R. ELLIS JUNIOR, 1962. Potassium ion fixation, equilibria, and lattice changes in vermiculite. Proceedings of Soil Science Society of America. Madison, 26: 230-233.

DE TURK, E.E.; L.K. WOOD e R.H. BRAY, 1943. Potash fixation in corn belt soils. Soil Science. Baltimore, 55: 1-12.

DOWDY, E, e T.B. HUTCHESON, 1963. Effect of exchangeable potas sium level and drying on release and fixation of potassium by soils as related to clay mineralogy. Proceedings of - Soil Science Society of Amerlca. Madison, 27: 31-34. 
FERTILIZANTES, 1987. OEstado de São Paulo. São Paulo, 16 set. 1987 , no 1668 , Suplemento Agrícola, p. 9.

GAMA, M.V., 1961. Sobre o método de Voik para a avaliação da capacidade de fixação de potássio dos solos. Agronomia Lusitana. Lisboa, 23: 116-128.

HARRIS, H.C., 1937. Effect of lime on the availability and the fixation of potash in soil. Soil science. Baltimore, 44: $265-275$.

JACKSON, M.L., 1956. Soils chemical analysis. Advanced course. Madison, Wis., Univ. of Wis. 991 p.

JACKSON, M.L., 1976. Analisises quimica del suelos. 3a ed., Barcelona, Omega. $662 \mathrm{p}$.

JOFFE, J.S. e L. KOLODNY, 1936. Fixation of potassium in soils. Proceeding of Soil Science Society of America. Madison, 1: $187-192$.

JOFFE, J.S. e L. KOLODNY, 1938. The effect of alternate drying wetting on the base-exchange complex with special reference to the behavior of the potassium ion. Proceeding of Soil Science Society of America. Madison, 3: 107-111. 
JOFFE, J.S. e A.K. LEVINE, 1946. Fixation of potassium in re lation to exchange capacity of soils: I. Release of fixed potassium. Soil Science. Baltimore, 62: 411-420.

JOFFE, J.S. E A.K. LEVINE, 1947. Fixation of potassium in relation to exchange capacity of soils: III - Factors contributing to the fixation process. Soil Science. Baltimore, 63: $241-147$.

19

KILMER, V.J. e V.T. ALEXANDER, 1949. Methods of making mecha nical analysis of soil Soil Science. Baltimore, 68: 15 26 .

LOPES, A.S., 1982. Mineralogia do potássio em solos do Brasil. In: YAMADA, T. Potássio na Agricultura Brasileira . Piracicaba, Instituto da Potassa \& Fosiato. Instituto Inter nacional da Potassa. p. 51-65.

MARTINI, J.A. e A. SUAREZ, 1947. Potassium supplying and fixing capacity of some Costa Rica Latosols and Andosols de termined by successive cropping, extractions, and incubations Soil Science. Baltimore, 123(1): 37-47. 
MATTHEUS, B.C. e G.G. SHERRELL, 1960. Effect of drying on exchangeable potassium of ontario soils and the relation of exchangeable potassium to crop yield. Canadian Journal of Soil Science. Otawa, 40: $35-41,1960$.

MATTHEUS, B.C, e P.H.T. BECKETT, 1962. A new procedure for studying the release and fixation of potassium ions in soil. Journal of Agricultural Science. Great Britain, 58: 59-64.

MIELNICZUK, J., 1982, o potássio no solo. Boletim Técnico no 2. 2a ed. Piracicaba, SP. Instituto da Potassa e do Fosfato. Instituto Internacional da Potassa. 78 p.

MOSS, P., 1963. Some aspects of the cation status of soil mois ture. I. The ratio law and soil moiusture content. Plant and Soil. The Hague, 18: 99-113.

MOSS, P. E J.K. COULTER, 1964. Potassium status of volcanic soils. Journal of Soil Science. Oxford, 15: 297.

NEVES, L.E., 1968. Estudo prático de argila por difratometria de raio-X. Boletim Técnjco da Petrobras. Rjo de Janeiro, 11: (1): $123-135$ 
PAGE, J.B. e L.D. BAVER, 1939. Ionic size in relation to fixation of cations by colloiday clay. Proceedings of Soil Science Society of America. 4: 150-155.

RAFAHI, H., 1980. Properties physico-chimiques et mineralogi ques des sols Bruns calcairis de L'Iran, retrogradation du Potassium. Canadian Journal of Soil Science. Ottawa, 60: $119-126$.

RANEY, W.A. E C.D. HOOVER, 1946. The release of artificially fixed potassium from a kaolinitic and montmorilonitic soil. Proceeding of Soil Science Society of America, Madison, 11: $231-237$.

REITEMEIER, R.F., 1951. Soil potassium. Advances in Agronomy. 3: $113-159$.

RICH, C.I. Aluminum in interlayers of vermjculite. Proceeding of Soil science Society of America. Madison, 24:26:32. 1960.

RICH, C. I e W.R. BLACK, 1964. Potassium exchange as affected by cation size, $\mathrm{pH}$, and mineral structure. Soil Science Baltimore, 97: 384-390. 
RICHARDS, G.E. e E.O. MCLEAN, 1963. Potassium fixation and release by clay minerals and soil clays on wetting and drying. Soil Science. Baltimore, 95(5): 308-314.

SCOTT, A.D.; J.J. HANWAY E E.M. STICKNEY, 1957. SOIl potas sium moisture relations. Proceeding of Soil Science Society of America. Madison, 23: 498-501.

STANFORD, G., 1947. Fixation of potassium in soils under moist conditions and on drying in relation to type of clay mineral. Proceedings of Soil Science Society of America. Madison, 12: $167-171$.

STANFORD, G. e W.H. PIERRE, 1946. The relation of potassium fixation and ammoniuin fixation. Proceedings of Soil Science Society of America. Madison, 11: 155-160.

TEIXEIRA MENDES, A.C., 1972. Identificação das argilas do solo por difração do raio-X. Piracicaba. ESALQ, USP, $34 \mathrm{p}$.

Van DER MAREL, H.W., 1954. Potassium fixation in Dutch soils: mineralogical analyses. Soil Science. Baltimore, 69: 261271. 
Van REEUWIJK, L.P. e J.M. VILLIERS, 1968. Potassium fixation by amorphous aluminosilica gels. Proceedings of Soil science Society of America. Madison, 32(2): 238-240.

VOLK, N.J., 1934. The fixalion of potash in difficultty available form in soils. Soil Science. Baltimore, 37: 267-287

Von AMBERGER, A.; R. GUTSER e K. TEICHER, 1974. Kaliumernahü rung der Pflanzen und kaliumdynamek auf kaliumfixierendem baden. Plant and Soil. The Hague, 40: 269-284.

WEAR, J.I. e J.L. WHITE, 1951. Potasium fixation in ciay minerals as related to crystal structure. Soil science. Baltmore, $\underline{71}(1): 1-14$.

WELTE, E. e E.A. NIEDERBUDDE, 1965. Fixation and availability of potassium in loess derived and alluvial soils. Journal of Soil Science. Oxford, 16: 116-120. 